\title{
Experimental and numerical assessment of the shear behaviour of lime mortar clay brick masonry triplets
}

\author{
D.V. Bompa ${ }^{1,2^{*}}$, A.Y. Elghazouli ${ }^{1}$ \\ ${ }^{1}$ Department of Civil and Environmental Engineering, Imperial College London, SW7 2AZ, UK \\ ${ }^{2}$ Department of Civil and Environmental Engineering, University of Surrey, GU2 7HX, UK
}

\begin{abstract}
This study investigates the fundamental shear response of masonry triplets incorporating fired-clay bricks and hydraulic lime mortars. It examines the behaviour under ambient-dry and wet conditions, corresponding to $48 \mathrm{~h}$ submersion in water, as well as the effectiveness of strengthening with fibre reinforced polymer (FRP) laminates and glass fibre meshes (GFM). After describing the materials, mix designs and specimen details, the main results from 50 triplet tests subjected to shear and normal pre-compression are presented. Digital image correlation measurement techniques, which are employed in order to obtain a detailed insight into the shear behaviour, enable clear identification and quantification of the main failure modes and response characteristics of the brick-mortar interfaces. The results show that the shear strength of wet triplets was about $20 \%$ lower on average than of those in dry conditions. Specimens provided with FRP sheets offered a higher strength enhancement than those with GFM. The strength increase using FRP was in the range of 16.6\%-185.8\% compared with the non-strengthened dry counterpart, depending on the laminate layout and normal stress level. In contrast, the strength increase using GFM, in conjunction with a mortar overlay, was typically less than $10 \%$ compared with the non-strengthened dry counterpart. A significantly higher strength contribution from both FRP and GFM was obtained for elements without pre-compression. Although the strength enhancement using GFM was generally modest, such strengthening is activated gradually leading to a relatively ductile interfacial behaviour in comparison with FRP. In order to provide further insights into the behaviour, complementary nonlinear numerical simulations are undertaken, using the key parameters obtained from the tests. The numerical models employ detailed surface-based cohesive-contact approaches, with due account for inelastic damage at the masonry interfaces, and damage-plasticity modelling for the constitutive response of brick materials. It is shown that the numerical approaches adopted are able to capture reliably the main behavioural characteristics and failure modes, and can therefore be employed for further numerical assessments.
\end{abstract}

Keywords: Clay bricks; lime mortar; shear response; fibre reinforced polymer, glass fibre mesh

*Corresponding author: Dr D.V. Bompa

Emails:DrD.V.Bompa (d.bompa@surrey.ac.uk),Prof A.Y.Elghazouli (a.elghazouli@imperial.ac.uk) 


\section{Introduction}

Heritage masonry is characterised by high material heterogeneity, irregular bearing elements and degradation of constituents due to environmental effects. It is recognised that environmental wetdry cycling can affect both the mechanical characteristics of masonry as well as plaster and rendering [1-3]. Moisture within masonry walls can have a detrimental effect on buildings and may undermine their long-term durability and integrity [4,5]. This occurs primarily due to the porosity and absorption rate properties of the bricks [6]. As masonry elements are intrinsically composite, besides brick and mortar properties, brick-mortar bond interactions govern their mechanical response. Brick absorption properties affect the bond strength as well as the moisture transfer between components, and also control the setting and hydration properties of the mortar [5]. A fundamental understanding and quantification of moisture effects on the mechanical properties of porous building materials such as masonry is hence required [7]. Besides degradation resulting from physical weathering, low strength and brittle nature of constituent materials, absence of diatones in multiple leaf masonry and poor wall-to-diaphragm floor connections, among others, are causes of vulnerability to seismic events for heritage masonry structures [8-10].

Unreinforced masonry (URM) walls can develop shear- or flexure-governed failures depending on their geometry, aspect ratio and boundary conditions. Shear failures are either characterised by inclined cracks, or by a sliding crack when a portion of the wall along a bed joint slides horizontally under lateral loads. The diagonal shear and sliding strength of URM is greatly dependent on the mortar-brick interaction. In general the interface mortar-brick shear response greatly depends on the moisture content, porosity, mortar strength, and conditioning type [11,12], with saturation causing a deterioration in strength and stiffness $[13,14]$.

In order to withstand lateral loading, structures must possess adequate strength and ductility to meet the imposed demand. For URM elements that are naturally brittle, this can be achieved through various strengthening approaches $[15,16]$. Possible strengthening techniques and materials for the retrofitting of URM elements depend on the availability of resources as well as the use and characteristics of the structure $[17,18]$. Other factors include the response of the selected retrofitting materials to overloading conditions [19] and their deterioration properties [20]. In broad terms, strengthening methods can be classified as either surface strengthening or, alternatively, incorporation of strengthening elements inside the masonry.

Strengthening of URM using fibre reinforced polymer (FRP) laminates is an attractive solution due to the high strength-to-weight ratio of these composite retrofitting materials. The composites act as 
tensile reinforcement increasing the in-plane shear and out-of-plane bending capacity of a strengthened wall $[22,23]$. FRP laminates used on URM can significantly enhance the strength and post-peak behaviour, altering the failure modes and maintaining the structural integrity [22, 24, 25]. These can also be used for external confinement in vertical masonry elements [26]. The performance of the strengthening system depends on the properties of the composites, in terms of the nature of the fabric, fibre orientation and overlapping length [27], as well as on the adopted retrofitting scheme [28]. Diagonal strengthening schemes typically show higher effectiveness than squared grids, as these act as tensile reinforcement perpendicular to the principal tensile/cracking stress, and can shift the failure modes from shear-governed to panel-rocking modes [29,30].

Strengthening by reinforced coatings requires a reinforcing material, typically in the form of a mesh, and an overlay in the form of mortar, plaster or shotcrete. Reinforcement materials can include a bi-directional expanded wire mesh [30,31], orthogonal meshes with hot-rolled ribbed wires [32], and polymeric or fibre reinforced polymer meshes. Reinforced coatings can include relatively flexible fibre materials such as carbon, glass, basalt [20,32-34], polypropylene, or polyester [15, 33, 35,36], as well as relatively stiff biaxial orthogonal geogrids [37], or triangular monolithic polymer grids [38]. The grids are typically embedded in conventional cement-based mortars, high performance mortars [32] or more sustainable lime-based mortars [31, 32, 39].

The shear and flexural performance of URM under lateral loading is characterised by the mortarbrick interface properties as well as the strength and relative stiffness of the two constituents. Diagonal shear failures or horizontal sliding mechanisms are primarily governed by the interface properties and these can be quantified through triplet tests [40]. As discussed above, a wide range of studies on the compression properties of wet masonry elements incorporating lime mortars and clay bricks exist [1-3, 7, 13, 14], whilst studies focusing on in-plane shear are limited [11]. Shear response of masonry was typically tested on dry triplets [40-43], and a significant amount of studies on both wet and dry cement mortar masonry were carried out to date [24,44]. Although textile reinforced mortar strengthening systems are more compatible with masonry substrate [21,45], most of the in-plane shear studies focus on strengthening with FRP laminates [46,47]. Additionally, detailed full-field measurements of in-plane shear behaviour of non-strengthened lime mortar - clay brick masonry are limited [48], whilst those on strengthened elements typically focus on the bond performance in FRP-brick components [49,50]. Also, although a variety of modelling techniques for masonry exist [51], the interface response is governed by the properties of constituent materials, and an assessment of these properties seems to be lacking for the materials considered in this paper. 
In order to provide fundamental insights into the interfacial behaviour and inform possible strengthening strategies of heritage structures, this paper describes tests carried out on: (i) nonstrengthened ambient-dry and wet specimens, corresponding to $48 \mathrm{~h}$ submersion in water; and (ii) strengthened triplets with fibre reinforced polymer sheets or glass fibre mesh and lime mortar overlay. The triplets were subjected to various levels of axial pre-compression. The properties of fired-clay bricks/lime-mortar triplets were selected to resemble those of masonry components investigated in a wider research programme on the management and conservation of heritage masonry structures in Historic Cairo [52]. As one of the objectives of the research programme is to offer detailed safety evaluation of such structures using non-linear computational models, numerical validation studies are also carried out to assess the main brick-mortar interface characteristics. Hence, using the key parameters obtained from the tests, this paper also provides a complementary numerical study, which provides further insights into the behaviour, and offers a validated approach which can be employed for detailed modelling of masonry elements.

\section{Experimental methodology}

\subsection{Material properties}

\subsubsection{Mortars}

Mortars incorporating natural hydraulic lime (NHL) with a binder-to-aggregate ratio of 1:3 were selected for the study. These are typically used for conservation works on historic masonry as walls can breathe naturally ensuring an enhanced long-term performance [20]. An eminently hydraulic binder (NHL5) [53], with a specific gravity of 2.70 was used in the lime mortars. The binder contains silicates, calcium aluminates and calcium hydroxide, obtained by firing of crushed marl limestone in kilns [54]. After removal from kilns, the limestone is subjected to slaking (hydration), which involves the addition of controlled amounts of water and then ground to powder [55]. These are singular binders which combine hydraulic with air setting, obtained by carbonation with atmospheric $\mathrm{CO}_{2}$. The free lime $\mathrm{Ca}(\mathrm{OH})_{2}$ content is above $15 \%$ for NHL5, whilst the sulphates content is below $2 \%$.

In addition to tap water, 'soft sand', typically used for bricklaying and pointing applications [56], was added to all mortar mixes. This type of sand has rounded particles and is essential for enhanced mix workability in comparison to sharp sand [57]. The specific gravity of the sand is 2.65, its water absorption is around 5\% and its gradation curve [58] is as illustrated in Figure 1a. A standardised mixing procedure was followed to produce mortars in 20-litre batches using a rotary mixer [53,59]. 
The dry constituents were mixed together for a period of $180 \mathrm{~s}$, followed by the gradual addition of water, and were then further mixed for another $180 \mathrm{~s}$. The consistency of fresh mortar was assessed by means of a flow table [60] and the flow was about $190 \mathrm{~mm}$. After casting, fresh mortar samples were covered with a plastic sheet and removed from moulds after five days. These were then kept near the masonry specimens in laboratory conditions.

Compressive strengths were determined from compression tests according to EN 1015-11 [61] on 12 cubes $(50 \times 50 \times 50 \mathrm{~mm})$, equally divided in ambient-dry and wet samples. Note that the wet conditioning corresponds to $48 \mathrm{~h}$ submersion of samples in water prior to testing, and that the wet samples were tested after being removed from water. Close inspection of the data obtained from submersing mortar samples in water for a period of $24 \mathrm{~h}$, indicated that after $3 \mathrm{~h}$, these had a relatively constant weight. It is hence considered that for the geometries investigated in this paper, submersion for $48 \mathrm{~h}$ is sufficient for saturation. After carefully measuring all dimensions using a digital calliper, the specimens were tested in compression at a displacement rate of $0.25 \mathrm{~mm} / \mathrm{min}$. These tests were carried out at $41 \pm 1$ days from preparation.

The resulting strengths of the mortar in ambient-dry conditions was $1.29 \pm 0.09 \mathrm{MPa}$. Figure $1 \mathrm{~b}$, which depicts the constitutive response of lime mortars under ambient-dry and wet conditions, shows that moisture reduces the compressive strength and the elastic modulus by about 55\% and $43 \%$, respectively, compared to those of ambient-dry mortar samples. Slightly lower strengths than expected for a mortar incorporating NHL5 lime were obtained, primarily due to relatively high temperatures $\left(28 \pm 2^{\circ} \mathrm{C}\right)$ and low humidity levels during the setting period. These relatively low strengths are, however, typical for heritage structures and can be as low as $0.35 \mathrm{MPa}$ [62-64]. Lower strengths of NHL mortars than those indicated by the manufacturer are obtained when the aggregates and the water quantity, as well as mixing procedures, are different from those that are standardised [62].

It is worth pointing out that the elastic modulus of mortar employed in the numerical assessments described in Section 4, was obtained from tests on cylindrical samples of $75 \mathrm{~mm}$ diameter and 150 $\mathrm{mm}$ height. The elastic modulus was calculated on the stress range of $30-50 \%$ by dividing the measured compression stress by the material strain. The material strain was obtained by dividing the average displacements recorded from three transducers by the gauge length of $100 \mathrm{~mm}$. The transducers were attached by two steel rings symmetrically positioned from the centre of the sample. However, it should be noted that the strength and stiffness decrease ratios of 55\% and $43 \%$ between dry and wet hardened mortars, respectively, were obtained from direct correlation of tests 
on cubic samples and only relative values are reported. Although sample shape and geometry would influence the strengths, for such poor material properties the ratios between dry and wet would be maintained [39].

Additionally, the moisture content of both conditioning cases (i.e. ambient-dry and wet) for NHL mortar samples was assessed. The ambient-dry samples and those submersed in tap water for a minimum of $48 \mathrm{~h}$, were dried in an oven for $6 \mathrm{~h}$ at $60^{\circ} \mathrm{C}$ and another for $18 \mathrm{~h}$ at $105^{\circ} \mathrm{C}$ until the sample mass was relatively constant. The moisture content of the lime mortars was $2.54 \%$ by weight (wt.\%) for ambient-dry samples and 10.80 (wt.\%) for those submersed in water.

\subsubsection{Bricks}

Commercial fired clay facing solid bricks were used for the construction of the shear triplets [65]. The measured sizes on an average of 30 samples were $229 \times 111 \times 66 \mathrm{~mm}( \pm 2.0 \times 2.9 \times 0.8 \mathrm{~mm})$. Such variation is common for bricks produced through slop moulding. The nominal compressive strength for elements tested perpendicular to bed face, as provided by the manufacturer is $13 \mathrm{MPa}[65,66]$. To assess the actual material properties of brick units, compressive tests parallel and perpendicular to the bed face were carried out. The faces in contact with the support/loading plates or bearings were ground in order to achieve planeness and parallelism [67]. The compressive strengths of brick units perpendicular to the testing bed, assessed from a minimum of three samples were 9.00 MPa in ambient-dry conditions and $8.86 \mathrm{MPa}$ in wet conditions. Tests on bricks parallel to the testing bed, showed that the average compressive strength, also obtained from a minimum of three tests, was 15.5 $\mathrm{MPa}$ in dry conditions and 15.6 in wet conditions.

The effect of moisture was investigated in another study in which tests on brick cylinders of 69.4 $\mathrm{mm}$ diameter with various aspect ratios and small walls under compression were carried out [14]. Depending on the specimen geometry and aspect ratio, the reduction in compressive strength due to moisture was up to $13 \%$ for brick cylinders with aspect ratio around 2.0. Note that the wet conditioning corresponds to $48 \mathrm{~h}$ submersion of brick samples in water that is sufficient to reach an adequate level of saturation. Close inspection of the data obtained from submersing brick samples in water for a period of $24 \mathrm{~h}$, indicated that after $3 \mathrm{~h}$ these had a relatively constant weight.

The specific weight of the bricks is $17.1 \mathrm{kN} / \mathrm{m}^{3}$. The freeze/thaw resistance category of the firedclay bricks from this study, as specified by the manufacturer, is F2 and corresponds to severe exposure conditions [66]. The classification for the active water soluble salts content category is S0, indicating no requirements for salts content. The latter is related to the soluble salts naturally occurring in clays used for brick manufacturing [66]. Parameters F2 and S0 are specified by the 
manufacturer and have minimal or no implications on the results and focus of this paper. As in the case of the lime mortar samples, the moisture content of bricks was assessed using the same conditioning procedure. The moisture content of ambient-dry bricks was $0.07 \%$ by weight (wt.\%), and $10.46 \mathrm{wt} . \%$ for those submersed in water. These values are in close agreement to those provided by the manufacturer (water absorption $\mathrm{w}_{\mathrm{a}}<10 \%[65]$ ).

\subsubsection{FRP laminates}

One layer of aramid FRP sheets (AFRP) was adopted to strengthen the triplets using a commercial moisture-tolerant EP epoxy bonding adhesive [67]. FRP laminate strips of $100 \mathrm{~mm}$ were bonded using a wet lay-up procedure in the horizontal direction, perpendicular to the bed joint, as well as following the specimen diagonal at $45^{\circ}$ to the bed joints (Figure 2). These two cases were representative of strengthening details at the edge/corners of a masonry wall, and its centre/diagonal, respectively. The aramid fibre (of Grade S\&P A120/290) was unidirectional and had $0.2 \mathrm{~mm}$ design thickness with a total sheet weight of $320 \mathrm{~g} / \mathrm{m}^{2}$ [68]. The mechanical properties provided by the manufacturer were as follows: mean elastic modulus of $116 \mathrm{GPa}$, mean tensile strength of $2400 \mathrm{MPa}$ and a strain fibre capacity of 2.5\%, whilst those obtained from uniaxial tests on $50 \mathrm{~mm}$ coupons width and $250 \mathrm{~mm}$ length were: $107 \mathrm{GPa}, 2035 \mathrm{MPa}$ and $1.9 \%$, respectively.

\subsubsection{Glass-fibre mesh}

An alkali-resistant E-glass fibre mesh (GFM) typically used in conjunction with render mortars was used as an alternative strengthening method [69]. The $4.0 \mathrm{~mm} \times 4.0 \mathrm{~mm}$ mesh with a weight-tosquare metre of $160 \mathrm{~g} / \mathrm{m}^{2}$ was incorporated into a lime mortar layer of 5-8 mm, which was prepared in the same proportions as the NHL5 lime mortars described above. This mortar was chosen to maintain the compatibility between the material properties of the masonry substrate and those in the lime-mortar render matrix. The E-glass fibre mesh is a relatively low-cost and low-strength material which has a tensile strength of $2.07 \mathrm{kN} / 50 \mathrm{~mm}$ along the warp direction and about 2.18 $\mathrm{kN} / 50 \mathrm{~mm}$ along the weft direction. The ultimate longitudinal elongation is lower than $3.3 \%$ and its lateral elongation below 2.7\%. Two bonding alternatives between triplets and glass-fibre meshes were considered. These are representative for boundary regions and for inner regions of a masonry wall. The former included epoxy resin bonding, whilst the latter used mechanical fasteners. Details of the two configurations are given in Section 2.2.

\subsection{Specimen details}

This section describes the specimen configuration, conditioning and testing methods employed to assess the shear strength of masonry triplets under non-strengthened (ambient-dry and wet) and 
strengthened (FRP and glass fibre mesh) conditions (Figure 2). A total of 50 specimens of $\mathrm{b} \times \mathrm{h} \times \mathrm{t}=$ $227 \times 229 \times 111 \mathrm{~mm}( \pm 2.8 \times 2.0 \times 2.9 \mathrm{~mm})$, were subjected to varying levels of pre-compression $\left(\sigma_{\mathrm{c}}\right)$. The specimen reference adopts the format Txyyz, where $\mathrm{x}$ indicates the specimen conditioning (nonstrengthened: D for dry W for wet; strengthened with FRP laminates: FH for horizontal layout, FD for diagonal layout; strengthened with glass fibre mesh (GFM) and render: TA for resin bonded mesh, TB for mechanically tied mesh, yy represents the pre-compression stress (e.g. 00 for $0 \mathrm{MPa}$, and 15 for $1.5 \mathrm{MPa}$ ), and $z$ represents the specimen sequence (a, b, c, etc.). Full details of the specimen preparation including application of the FRP laminates and GFM are described below. It is worth noting that the measured brick sizes on average were $229 \times 111 \times 66 \mathrm{~mm}( \pm 2.0 \times 2.9 \times 0.8$ $\mathrm{mm})$, whist the mortar joint thickness was $14.4 \pm 1.4 \mathrm{~mm}$.

Specimens TD and TW were tested in the first stage and $\sigma_{\mathrm{c}}$ was between 0-2.5 MPa. After an initial analysis of the failure modes and test results, the strengthened triplets (TFH, TFD, TTA, TTB) were subjected to $\sigma_{\mathrm{c}}=0-1.5 \mathrm{MPa}$ only, as these ranges are more representative of the heritage structures analysed in the project [52]. Between one and three specimens were tested for each precompression level for non-strengthened Specimens TD and TW, and only one specimen was tested for the strengthened triplets (TFH, TFD, TTA, TTB). On the one hand, a lower number of specimens per configuration allow for experiments on a wider range of parameters. This enables a broader understanding of the influence of various parameters on the response of masonry elements, for the same experimental resources. In contrast, a relatively low number of samples per configuration would also restrict the reliability of the results, particularly for masonry tests which pose a high degree of uncertainty.

For heritage masonry such as that investigated in this project [52], the precompression levels are around 1.0 $\mathrm{MPa}$ and for this reason the applied precompression in the strengthened triplets was limited to $1.5 \mathrm{MPa}$. However, in the non-strengthened specimens, the aim was to identify limit conditions for a wider range of precompressions in order to understand better how confinement of the mortar joints affects the shear-compression behaviour. On another note, the mortar joint is a triaxial compression stress state and as any cohesive-brittle material, would be able to carry precompression levels higher than its uniaxial compression strength.

Only ambient-dry (TD) and wet (TW) specimens were considered for this study. From a total of 30 non-strengthened specimens, 15 were kept in laboratory conditions $\left(\mathrm{T}=24-30^{\circ} \mathrm{C}, \mathrm{RH}=30-50 \%\right)$ as shown in Figure 3a, whilst the remaining 15 specimens were tested in wet conditions. Results from the literature $[13,71,72]$ indicate that there is minimal or no influence of moisture on the mechanical 
properties of the materials, when the moisture content is below 3\% by weight. Note that the wet conditioning (Specimens TW) corresponds to $48 \mathrm{~h}$ submersion of samples in water. Close inspection of the data obtained from submersing masonry specimens and independent masonry components (bricks, mortar samples and bricks with mortar joints) in water for a period of $24 \mathrm{~h}$, indicates that after $3 \mathrm{~h}$, the masonry specimens have a relatively constant weight. It is hence considered that for the geometries investigated in this paper, submersion for $48 \mathrm{~h}$ is sufficient for saturation. These conditions are similar to those observed in historic sites such as those investigated as part of this project [52].

A total of 20 strengthened specimens, equally divided in 4 groups as described above, were tested under shear loading and ambient-dry conditions only. Specimens TFH and TFD, were provided with aramid FRP laminate strips of $100 \mathrm{~mm}$, bonded in horizontal direction, perpendicular to the bed joint, as well as following the specimen diagonal at $45^{\circ}$ to the bed joints. Prior to applying the AFRP sheets, the masonry surfaces were brushed, cleaned using compressed air, and provided with a two-component epoxy resin primer (Figure $3 \mathrm{~b}$ ). The latter was used to seal and stabilise prepared surfaces prior to bonding fibre sheets for strengthening. As illustrated in Figure 3c, only one layer of aramid FRP (AFRP) sheets was applied using a hand wet lay-up procedure. To achieve this, the AFRP sheets were impregnated with a commercial moisture-tolerant EP epoxy bonding adhesive [67].

The remaining Specimens (TTA and TTB) were strengthened with glass fibre mesh (GFM) [69] and lime mortar render in the quantities described above. Two bonding conditions were considered independently in these specimens, namely: using epoxy bonding adhesive or mechanical fasteners. In practical applications, both systems would be used jointly as these would be employed at different locations within a masonry panel. To ensure appropriate bonding, for Specimens TTA, the fibre mesh was passed below the triplet and bonded with epoxy adhesive (Figure $3 \mathrm{~d}, \mathrm{e}$ ). On the other hand, Specimens TTB incorporated $6 \mathrm{~mm}$ steel mechanical fasteners provided with washers and nuts. For practical site conditions, these would be replaced with non-corrosive elements and would need to be distributed considering practical considerations (e.g. number of connectors per square metre). As depicted in Figure 3f, the mechanical fasteners were passed through pre-drilled holes of $8 \mathrm{~mm}$ diameter. Due to the inherent geometrical configuration of the triplet for shear testing, the 6 $\mathrm{mm}$ ties were passed through the bricks, rather than the mortar joint. In this way, the two shear planes between the three bricks of the triplets would not be altered. 


\subsection{Testing arrangements and instrumentation}

A stiff four-post hydraulic servo-controlled machine with a capacity of $750 \mathrm{kN}$ was used for testing the triplets in shear. The two lateral bricks of each triplet were positioned on $65 \mathrm{~mm}$ wide and 115 $\mathrm{mm}$ deep steel blocks, which were connected to the machine bed through a series of hinges (Figure 4). A $65 \mathrm{~mm}$ wide steel block and a hinge were used to transfer the load from the actuator to the central brick. As mentioned before, the triplets were subjected to direct shear with co-existing axial pre-compression to assess the properties of mortar-unit interfaces [72-74]. Prior to applying the monotonic displacement procedure to the central brick, a preload equivalent to axial stresses of up to 2.5 MPa was applied through four threaded ties and recorded by a load cell (denoted as ' 5 ' in Figure 4). The precompression load was applied and maintained by tying the four threaded ties using a hand-held spanner.

Besides the transducers used to record overall deformations, a digital image correlation (DIC) system was used to obtain displacements and strain fields from all triplet tests. This non-contact procedure offers a high level of accuracy and practicality compared to conventional mechanical instrumentation $[75,76]$. The DIC system consists of two light-weight CMOS camera with USB 3.0 interface for distances up to $25 \mathrm{~m}$. The high sensitivity cameras have a resolution of 2.3 Megapixel at $100 \mathrm{~Hz}$ frame rate. These are connected to a controller which also acts as a data acquisition system. As part of the preparation process, the specimens were firstly painted in white, and then carefully speckled with $0.5-2.0 \mathrm{~mm}$ black dots in order to create a high-contrast black-white pattern.

Prior to testing, a calibration procedure was undertaken by adjusting iteratively the aperture, ambient lighting and camera focus, while taking photos of a calibration plate adjacent to the specimen face. This was required to allow the post-processing software to determine the distance between the cameras and the specimen and, ultimately, to compute the surface strain vector fields. A frequency of $0.2 \mathrm{~Hz}$ for data recording was chosen to acquire a sufficiently large pool to minimise possible scatter [77]. After testing, the DIC data was further processed to obtain deformation vector fields. From these, surface strains or deformations were assessed from assigned virtual gauges with various lengths depending on the size of the specimen and brick layout.

\section{Test results}

\subsection{Shear stress versus slip}

Figure 5a,b illustrate the average shear stress versus displacement $\left(\tau-\delta_{\mathrm{s}}\right)$ curves for various values of pre-compression $\left(\sigma_{c}\right)$ for non-strengthened dry (TD) and wet (TW) specimens. The shear stress is 
the load recorded by the machine divided by the sum of the interface areas of a specimen parallel to the bed joints. (Figure 4). The shear displacement refers to the relative displacement between the central brick and lateral bricks and was obtained from the DIC data using virtual gauges as depicted in Figure 4. As observed, the shape of the $\tau-\delta_{\mathrm{s}}$ curves depends on the level of pre-compression $\sigma_{\mathrm{c}}$, with the shear strength $\tau_{\mathrm{m}}$ increasing proportionally with $\sigma_{\mathrm{c}}$. Additionally, the test results indicate a reduction in $\tau_{\mathrm{m}}$ for wet (TW) specimens in comparison with the dry (TD) counterparts for the same level of $\sigma_{\mathrm{c}}$. By comparing the $\tau-\delta_{\mathrm{s}}$ curves in Figure 5a,b, it can be observed that depending on $\sigma_{\mathrm{c}}$, $7-32 \%$ reductions in $\tau_{\mathrm{m}}$ occur between dry and wet cases. A relatively larger reduction of $\tau_{\mathrm{m}}$ around $48 \%$ is obtained for cases with $\sigma_{\mathrm{c}}=0 \mathrm{MPa}$. It is worth noting that since the failure at $\sigma_{\mathrm{c}}=2.0-2.5$ $\mathrm{MPa}$, as described in detail in Section 3.2 below, was due to brick cracking rather than interface slip, the corresponding results are not considered for assessment and the tests on strengthened triplets were limited to $\sigma_{\mathrm{c}}=0-1.5 \mathrm{MPa}$. The above results are in agreement with previous studies [78], which reported that for strong mortar with a cement-to-sand ratio of $1: 3, \tau_{\mathrm{m}}$ of dry clay brick masonry triplets reduces by around $33 \%$ for $\sigma_{\mathrm{c}}=0 \mathrm{MPa}$ in comparison to those in saturated conditions.

Tests on strengthened specimens showed an increase in shear strength $\tau_{\mathrm{m}}$ for all pre-compression ranges with $\sigma_{\mathrm{c}}=0-1.5 \mathrm{MPa}$ in comparison to their non-strengthened dry counterparts. As shown from the $\tau-\delta_{\mathrm{s}}$ in Figures $5 \mathrm{c}-\mathrm{f}$, besides the increase in $\tau_{\mathrm{m}}$, the strengthened specimens developed a softer post-peak response which is characterised by higher toughness and ductility. The material toughness is a property representing the resistance to crack propagation, directly governed by mechanical properties of the material and its geometry [79]. Toughness is represented by indices which are defined as ratios between the areas under the load-deformation or deflection curves at deflection limits defined by a particular codified procedure [80]. This measure was employed for comparative assessments in shear tests on push-off specimens as well as prisms in shear and flexure [81,82]. Toughness is considered here as the ratio between the area under the $\tau-\delta_{\mathrm{s}}$ curve up to $\delta_{\mathrm{s}}=30 \mathrm{~mm}$ and the area under the $\tau-\delta_{\mathrm{s}}$ curve up to the peak $\tau_{\mathrm{m}}$. Ductility on the other hand refers here to the ratio between $\delta_{\mathrm{s}}$ at $20 \%$ reduction of stress from $\tau_{\mathrm{m}}$ in the post-peak regime and $\delta_{\mathrm{s}}$ at $\tau_{\mathrm{m}}$. As expected, specimens provided with FRP sheets provided a higher strength enhancement than those with glass fibre mesh (GFM). Due to direct surface bonding between FRP laminates and masonry substrate, the FRP fibres are effectively activated when $\delta_{\mathrm{s}}$ corresponding to the $\tau_{\mathrm{m}}$ of nonstrengthened counterparts is reached, hence contributing directly to enhancing the member capacity. However, as the FRP material has a relatively high strength in comparison with the masonry 
components used herein, the specimen failure was governed by the brick and mortar tensile properties, rather than that of the FRP laminates.

When $\sigma_{\mathrm{c}}=0 \mathrm{MPa}$, the strength increase provided by the horizontal sheets (TFH Specimens in Figure 5c) was about eight-fold the non-strengthened specimens. Similarly, for those with diagonal sheets (TFD specimens in Figure 5d) this enhancement was about seven-fold. The complete strength $\left(\tau_{\mathrm{m}}\right)$ details are given in Table 1. This shows that the FRP laminates kept the brick-mortar interfaces together and were effective at restricting slip and maintaining the masonry integrity. For $0.25 \geq \sigma_{c} \geq 1.5 \mathrm{MPa}$, the strength increase varied between 16.6-185.8\% for TFH Specimens in comparison with dry TD counterparts. Details of shear strength ratios of strengthened to nonstrengthened triplets are given in Table 1 . Also, for $0.25 \geq \sigma_{\mathrm{c}} \geq 1.5 \mathrm{MPa}$, the contribution to strength enhancement of diagonally placed laminates (TFD) specimens was between 30.7-86.0\% compared to the TD counterparts. As observed, a better performance was obtained for the case with horizontal FRP sheets, as the material fibres were perpendicular to the slip direction. In both cases (TFH and TFD), the strength enhancement was achieved with only limited contribution from the FRP laminates. The maximum strain levels on the sheet surface were in the range of $0.2 \%$, which is less than $10 \%$ of the ultimate material strain. Moreover, as shown in Figure 5c,d, after the peak strength is reached, the response is relatively brittle with $\tau$ generally dropping more than $20 \%$ after the peak.

In contrast to the TFH and TFD specimens, the glass fibre mesh (GFM) strengthened specimens (TTA and TTB) had a better post-peak performance, with a more gradual post-peak stress reduction with the increase in slip (Figure 5e,f). This is because the GFM is a low strength material with relatively high ductility. As expected, the contribution of such systems to $\tau_{\mathrm{m}}$ enhancement is limited. The results in this paper show that the combined contribution of the GFM and mortar overlay was less than $10 \%$ on average for $0.25 \geq \sigma_{c} \geq 1.5 \mathrm{MPa}$, in comparison to TD specimens. As for TFH and TFD specimens, the highest contribution to $\tau_{\mathrm{m}}$ was for the case with $\sigma_{\mathrm{c}}=0 \mathrm{MPa}$. The shear strength $\tau_{\mathrm{m}}$ of TTA and TTB at $\sigma_{\mathrm{c}}=0 \mathrm{MPa}$ were 4.6 and 5.7 times higher than those of the corresponding TD specimen. Both bonding techniques, through epoxy resin (TTA) and by mechanical anchoring (TTB) proved to be effective in restricting brick-mortar interface separation and maintained specimen integrity. In contrast to FRP-strengthened specimens, for which the $\tau_{\mathrm{m}}$ is governed by the brick and mortar properties and the FRP laminates are only partially activated, for TTA/TTB cases the GFM is fully activated and post-peak response is governed by gradual fracture of the glass fibres within the mesh. It is worth noting that for $\sigma_{\mathrm{c}}=0 \mathrm{MPa}$, the response of the triplets is mixed mode, characterised by combined shear displacement and tensile crack opening, whilst for $\sigma_{\mathrm{c}}>0 \mathrm{MPa}$, tensile crack opening is restricted and the response is governed by shear displacement 
only. This results in a significantly higher contribution from the strengthening systems for $\sigma_{\mathrm{c}}=0$ $\mathrm{MPa}$, which is otherwise relatively modest for higher $\sigma_{\mathrm{c}}$.

\subsection{Kinematics and failure modes}

Two main failure modes were observed for non-strengthened triplets as a function of the precompression stress. For both dry and wet tests, when $\sigma_{\mathrm{c}}=0 \mathrm{MPa}$, the failure initiated at one of the four brick-mortar interfaces propagating abruptly throughout the depth of the specimen. After the peak shear stress $\tau_{\mathrm{m}}$ was reached, as shown in Figures $6 \mathrm{a}, \mathrm{b}$ and $7 \mathrm{a}, \mathrm{b}$, the specimen separated into two distinct bodies and $\tau$ dropped instantaneously to zero. For triplets with $0.25 \geq \sigma_{\mathrm{c}} \geq 1.5 \mathrm{MPa}$, failure occurred on the faces of both sides of the mortar layer with multiple cracks forming inside each mortar layer. Within this range, the cracks in the mortar layers formed at an angle around $45^{\circ}$ toward the top of the central brick, following the principal stress fields. As the precompression stress was $\sigma_{\mathrm{c}} \geq 2.0 \mathrm{MPa}$, the fracture initiated at the bricks which showed signs of splitting. For high pre-compression of $\sigma_{c} \geq 2.0 \mathrm{MPa}$, close inspection on the DIC strain fields indicated a wider network of microcracks in wet brick units in comparison to dry conditions, which suggests that the bricks become softer and weaker under moisture. Moreover, the mortar from dry specimens had less cohesion, breaking in multiple lumps, whilst the mortar from wet specimens had less fracture surfaces due to paste-like consistency.

As mentioned above, for specimens with FRP laminates, the ultimate behaviour of the specimens was governed by the properties of the bricks and mortar, rather than the FRP sheets. As illustrated in Figures $6 \mathrm{c}, \mathrm{d}$ and $7 \mathrm{c}, \mathrm{d}$ the post-peak surface strains were characterised by large areas of cracking and spalling of the brick components. For example, for relatively low pre-compression of $\sigma_{\mathrm{c}}=0.25$ $\mathrm{MPa}$, the specimen with horizontal sheets (TFH02) showed horizontal splitting cracks in the right brick and vertical splitting cracks in the middle brick. As the bond between the sheet and brick was very high, the central brick was subjected to compression stresses higher than the brick compressive strength. As the pre-compression increases to $\sigma_{\mathrm{c}}=1.5 \mathrm{MPa}$, horizontal stresses along with confinement from the FRP sheet produced a more severe cracking in the triplet. In terms of overall behaviour, both TFH and TFD had similar responses with main difference resulting from the relationship between the FRP sheet angle and the brick-mortar slip direction.

The full-field DIC measurement data for GFM-strengthened specimens, as shown in Figure 6e,f and 7e,f, indicate a relatively random crack pattern. As the mesh was covered in a mortar overlay, the crack patterns depended on the mortar homogeneity. As mentioned above, for the TTA specimens the GFM was passed below the triplet and bonded with epoxy adhesive. Under shear loading, the 
mesh bonded to the middle brick was in tension following the slip direction. This is clearly illustrated through the crack patterns of TTA02 and TTA10 (Figure 6e) which show a trapezoidal region which split from the specimen surface and is pushed downwards, following the slip direction. For the second bonding case, Specimens TTB, which included $6 \mathrm{~mm}$ steel mechanical fasteners provided with washers and nuts, the only interaction between the central brick and the GFM was through the mortar adherence. Even in this case, the post-peak response was reliable and some enhancement in toughness was obtained in comparison with non-strengthened triplets. As both GFM-bonding mechanisms (i.e. epoxy resin and mechanical fasteners) performed well, a mix of the two would be required in practice, particularly since the TTA strengthening case is representative for boundary regions while TTB is typical of inner regions of a masonry wall.

\subsection{Shear-to-expansion displacement response}

The relationship between shear-to-expansion displacement ratio $\delta_{\mathrm{s}} / \delta_{\mathrm{w}}$ and the shear stress $\tau$ for selected triplets is illustrated in Figure 8a-f. The expansion displacement refers to the horizontal deformation of the brick-mortar-brick interface obtained from DIC data using virtual gauges located at the bottom of the specimen (Figure 4). The shear displacement refers to the relative displacement between the central brick and lateral bricks and was also obtained from the DIC data using virtual gauges as shown in the same figure. The shear displacements of mortar joints during the shear

loading of masonry is associated to volumetric expansion [83]. The tendency of mortar joints to dilate, when simultaneously subjected to shear stress and normal compression, increases the shear resistance because it opposes the compression force [84]. This is similar to aggregate interlock in concrete and similar materials [85,86]. Dilatancy of a masonry joint measured experimentally is expressed by a dilation angle which is a function of the normal-to-shear displacement $\left(\delta_{\mathrm{w}} / \delta_{\mathrm{s}}\right)$ ratio of the joint and a coefficient that accounts for the number of bed joints that contribute to the mechanism of dilatancy [87]. In this paper, an inverse representation of the normal-to-shear displacement ratio $\left(\delta_{\mathrm{w}} / \delta_{\mathrm{s}}\right)^{-1}$ was chosen as a measure for dilatancy only for comparative purposes. Hence, the $\tau$ versus $\delta_{\mathrm{s}} / \delta_{\mathrm{w}}$ curves can be used as a measure for the shear behaviour of masonry triplets, particularly to highlight the difference in response between different conditions: nonstrengthened dry or wet, strengthened with FRP or GFM.

Figure $8 \mathrm{a}$, which depicts the comparison between triplets with $\sigma_{\mathrm{c}}=0 \mathrm{MPa}$ (i.e. TD00 versus TW00), shows that one of the interfaces developed very little dilation, whilst the other had significantly higher $\delta_{\mathrm{s}} / \delta_{\mathrm{w}}$, supporting the observation that for $\sigma_{\mathrm{c}}=0 \mathrm{MPa}$, only one interface lost its adhesion. A slightly softer stiffness was observed for TW00 in comparison with TD00, indicating that some adhesion existed at both interfaces for the wet specimen. On the other hand, samples with $0>\sigma_{c}>2.0$ 
MPa showed relatively similar response (i.e. dry TD15 versus wet TW15 in Figure 8d). For the wet specimens, one of the interfaces had higher dilation up to about $80 \%$ of the peak stress, and the other side compensated up to the peak. In contrast, dry specimens had relatively similar $\delta_{\mathrm{s}} / \delta_{\mathrm{w}}$ at both interfaces. This indicates that the moisture conditions affect the response, producing some eccentricity in deformation.

A direct comparison between the $\tau$ versus $\delta_{\mathrm{s}} / \delta_{\mathrm{w}}$ curves of non-strengthened triplets and those provided with FRP or GFM, when $\sigma_{\mathrm{c}}=0 \mathrm{MPa}$, indicates that for the strengthened specimens, most of the dilation $\left(\delta_{\mathrm{s}} / \delta_{\mathrm{w}}\right)$ was concentrated at one of the brick-to mortar interfaces. Of particular interest are Specimens TTA00 and TFD00 which show that after a shear stress in the range $\tau=0.05 \mathrm{MPa}$ the strengthening system is activated (Figure $8 \mathrm{~b}$ ). For TTA00 provided with GFM, there is a gradual activation of the glass fibres, which is shown by the relatively constant $\tau$ versus $\delta_{\mathrm{s}} / \delta_{\mathrm{w}}$ stiffness for ranges of $\tau=0.05-0.15 \mathrm{MPa}$. On the other hand, for TFD00 provided with FRP sheets, the activation of the laminates is very little up to $\tau=0.35 \mathrm{MPa}$, which is followed by a plateau. As shown in Figure $8 \mathrm{c}$, the response of TFH00 is relatively similar, yet the $\delta_{\mathrm{s}} / \delta_{\mathrm{w}}$ is about half of TFD00.

Strengthened triplets subjected to relatively high precompression stresses $\left(\sigma_{\mathrm{c}}=1.5 \mathrm{MPa}\right)$, showed complementary $\tau-\delta_{\mathrm{S}} / \delta_{\mathrm{w}}$ response at the two interfaces. As shown in Figure 8e for Specimen TTA15 and Figure $8 \mathrm{f}$ for Specimen TFD15, the right interface had the highest contribution up to around $\tau=0.90 \mathrm{MPa}$ and then the left interface took over. At peak $\left(\tau_{\mathrm{m}}\right)$, these had nearly identical $\delta_{\mathrm{s}} / \delta_{\mathrm{w} . .}$ The test results show that both strengthening techniques can provide a similar physical behaviour. However, due to relatively low strength combined with high elongation properties, GFM seem to be a better alternative as this is activated gradually and enables relatively ductile interface behaviour.

\section{Numerical validation}

The numerical validations described in this section were carried out using the nonlinear finite element program ABAQUS [88] to obtain the brick-mortar interface characteristics for detailed modelling of masonry elements. The numerical models are validated against selected test results from both strengthened and non-strengthened members in terms of shear stiffness, shear strength and in-plane shear fracture energy.

\subsection{Modelling details}

Masonry modelling is broadly based on two main modelling approaches. When the brick-mortar interface behaviour is implicitly modelled through a set of homogenised properties of the element, the procedure is referred to as macro-modelling. Such approaches are generally adopted for 
modelling of large and complex structures when the global structural response is of interest $[51,89]$. In contrast, micro-modelling represents an alternative in which the interface response is explicitly modelled. From the wide range of modelling procedures available for masonry elements, a micromodelling block-based approach was considered herein for its ability to clearly identify failure modes as well as the advantage of using small-scale experimental test results as input $[51,90]$. In this method, masonry elements are modelled with discrete blocks and their interaction properties are represented by interface elements [91].

The numerical models adopted accounted for the full geometry of the triplets. Instead of modelling the mortar joint a simplified approach was employed herein. As indicated in Figure 9a, the brick units, modelled with three-dimensional eight-node continuum elements with reduced integration (C3D8R), were expanded to incorporate the mortar joint in the form of an equivalent brick. The brick-mortar interface was modelled with zero-thickness interface elements using a node-to-surface discretisation with finite sliding formulation. The interface properties employed a surface based cohesive-contact approach with due account for inelastic damage. In the triplet models, schematically illustrated in Figure 9b-d, the surfaces of the central brick were assigned as masters, whilst those from the two lateral bricks as slaves. In the cohesive contact modelling approach employed herein, cohesive calculations were computed at contact constraint locations, which were associated with slave nodes. On another note, a damage-plasticity model was used to model the response of brick materials.

\subsubsection{Interface properties}

The elastic contact properties were defined using a linear uncoupled traction-separation behaviour, illustrated schematically in Figure 9e, in which the tensile $\left(\mathrm{K}_{\mathrm{nn}}\right)$ and tangential stiffness $\left(\mathrm{K}_{\mathrm{ss}}\right.$ and $\left.\mathrm{K}_{\mathrm{tt}}\right)$ components were considered independently. The tensile stiffness $\left(K_{n n}\right)$ corresponds to the elastic properties preceding interface opening in the normal direction, whilst $\mathrm{K}_{\mathrm{ss}}$ and $\mathrm{K}_{\mathrm{tt}}$ are for elastic response prior to in-plane shear sliding (shearing) and out-of-plane shear sliding (tearing), respectively. These material properties need to be equivalent to the stiffness of the physical brickmortar interface and were determined with Equations (1 and 2) as a function of the elastic moduli of the mortar $\left(E_{m}\right.$ or $\left.G_{m}\right)$ and bricks $\left(E_{b}\right.$ or $\left.G_{b}\right)$ as well as the mortar joint thickness $\left(h_{m}\right)$ [92]. The relationship between the tensile or flexural modulus of elasticity (E) and shear modulus or modulus of rigidity $(\mathrm{G})$ is a function of the Poisson ratio of the material $(v)$.

Material properties used to determine the interface stiffness properties $\left(\mathrm{K}_{\mathrm{nn}}\right.$ and $\left.\mathrm{K}_{\mathrm{ss}}\right)$ of both mortars and bricks were assessed from tests on cylindrical samples with aspect ratio above two and are 
listed in Table $2[14,39,52]$. The mortar cylinders had a diameter of $75 \mathrm{~mm}$ and a height of 150 $\mathrm{mm}$, whilst the brick cylinders had a diameter of $69.4 \mathrm{~mm}$ and a height of $137 \mathrm{~mm}$ and were made of two stacked cores extracted from brick units. Cylindrical samples were used to assess the elastic moduli as a uniaxial stress state is developed at the centre of the specimen and possible triaxial confinement effects occurring due to load transfer and support plates in cubic tests are eliminated [93-95]. The elastic modulus was calculated on a stress range of 30-50\% by dividing the measured compression stress by the material strain. For the mortar properties, the material strain was obtained by dividing the average displacements recorded from three transducers by the gauge length of 100 $\mathrm{mm}$. The transducers were attached through two steel rings symmetrically positioned from the centre of the sample. For the brick cylinders, the strains were obtained from the DIC data from assigned virtual gauges with a length of $100 \mathrm{~mm}[14]$.

The test material properties used to determine $\mathrm{K}_{\mathrm{nn}}$ and $\mathrm{K}_{\mathrm{ss}}$ are as follows: brick elastic modulus $\mathrm{E}_{\mathrm{b}}$, mortar elastic modulus $E_{m}$, brick compressive strength $f_{b}$ and mortar compressive strength $f_{m}$. Based on existing literature, a Poisson ratio of $v=0.2$ was used for both mortar and bricks to determine the modulus of rigidity $(\mathrm{G})$, which are representative for the materials used in this paper [96,97]. Based on the material properties obtained from the tests described briefly above, the tensile stiffness $\mathrm{K}_{\mathrm{nn}}$ $=35.9 \mathrm{~N} / \mathrm{mm}$, whilst $\mathrm{K}_{\mathrm{ss}}=\mathrm{K}_{\mathrm{tt}}=15.0 \mathrm{~N} / \mathrm{mm}$.

$$
\begin{aligned}
K_{n n} & =\frac{E_{b} E_{m}}{h_{m}\left(E_{b}-E_{m}\right)} \\
K_{s s} & =\frac{G_{b} G_{m}}{h_{m}\left(G_{b}-G_{m}\right)}
\end{aligned}
$$

In the post-peak regime, the bond loss between the two interfaces were represented through a damage modelling approach which can represent degradation and eventual failure of the cohesive surfaces. With this modelling approach, the inelastic shear response of the cohesive interface is activated when a damage initiation criterion is met, typically represented by a maximum nominal shear stress $\left(\tau_{\mathrm{m}}\right)$ or a maximum separation $\left(\delta_{\mathrm{s}}{ }^{0}\right)$. Once the criterion is met, damage occurs according to a user-defined damage evolution law. In this study, the damage initiation criterion was specified in terms of strength (i.e. $\tau_{\mathrm{m}}$ ) and a linear descending damage evolution law, by means of an in inplane shear fracture energy criterion $\left(\mathrm{G}_{\mathrm{fs}}^{\mathrm{ss}}\right)$, were considered using the test results from Table 3 . The value of $\tau_{\mathrm{m}}$ was also based on the test results. In the absence of experimental data for similar configurations to those examined herein, $\tau_{\mathrm{m}}$ can be assessed by employing a Mohr-Coulomb criterion (Equation 3 and Figure 9f) using the model coefficients $\mathrm{c}$ and $\mu$ indicated in Figure 10. In addition to the cohesive surface properties, normal-direction behaviour using regular contact 
properties were defined as a typical representation of masonry behaviour. Hard contact was assigned to interacting surfaces by means of a non-cohesive contact pressure-overclosure relationship, which restricts surface penetration and transfer of tensile stresses between interfaces.

$$
\begin{aligned}
& \tau_{m}=c+\mu \sigma_{c} \\
& (c, \mu)=\mid \begin{array}{l}
0.165,0.619 \rightarrow T D \\
0.100,0.578 \rightarrow T W \\
0.578,0.592 \rightarrow T F H \\
0.457,0.747 \rightarrow T F D \\
0.334,0.565 \rightarrow T T A \\
0.343,0.510 \rightarrow T T B
\end{array}
\end{aligned}
$$

\subsubsection{Brick properties}

A damage-plasticity model was used to represent the inelastic response of expanded brick units. This model considers a non-associated potential plastic flow with a default eccentricity $\epsilon=0.1$ and can simulate the tri-axial behaviour of cohesive-brittle materials. The three-dimensional yield surface is controlled by a shape parameter $K_{c}=0.667$, with the ratio between the biaxial and uniaxial compressive strength as $f_{b} / f_{c}=1.16$. The above default parameters were used for all analyses. A relatively low viscosity parameter of $1 \times 10^{-5}$ was chosen for the analysis to ensure convergence but minimise the influence of viscous strains on the numerical response. The non-associative plastic volumetric deformations of the material are not directly proportional to the changes in stresses and these are represented by a dilation angle $\psi$, which was considered herein as $10^{\circ}$ to represent the relatively brittle material response. It is worth noting that the damage-plasticity parameters play a significant role on the response of confined materials subjected to high levels of compression. However, the test observations from this paper indicate that the bricks were largely in the elastic regime and the compression crushing strain was not reached. The values of the main damageplasticity constitutive parameters are therefore unlikely to influence the calibration of the masonry joint interface properties. Close inspection of the results of a sensitivity study in which the dilation angle was varied in the range of $10-50^{\circ}$ showed that there was very little influence on the numerical load-displacement curves.

The model requires two independent material functions to describe the uniaxial stress-strain $\sigma-\varepsilon$ relationships of clay bricks under compression and tension, considering the damage parameters $d_{i}$ $(i=c, t)$ to represent the stiffness degradation of the material (Equation 4). In this investigation, a plastic degradation model was applied based on the assumption that the damage occurs in the softening range only. 


$$
d_{i}=\left\{\begin{array}{l}
0 \rightarrow \varepsilon<\varepsilon_{i} \\
1-\sigma_{i} / f_{c i}
\end{array} \text { where } i=c, t\right.
$$

The compressive material properties of bricks were obtained from cylindrical cores with aspect ratios around two, extracted from brick units, as described before [14]. The ultimate compressive strain was calculated based on an energy-based formulation considering the material crushing energy $G_{c l}$ represented by the area under the softening stress-strain curve in Figure $9 \mathrm{~g}$, and a parameter $1_{\mathrm{m}}$ which is the characteristic length being equal to the mesh size. As shown in Figure $9 \mathrm{~h}$, a linear representation of the softening branch was taken into consideration in tension for computational efficiency, in which the ultimate crack mouth displacement $\mathrm{w}_{\max }$ was obtained from test results on prismatic samples with square cross-section $[39,52]$. These were obtained by cutting brick units in two elements with a diamond saw. The sample length was the same as a brick unit $(\approx 229 \mathrm{~mm})$, whilst its depth and width were both $51 \pm 1.5 \mathrm{~mm}$. A notch of $5 \mathrm{~mm}$ depth was then created using a grinder provided with a diamond disc [39]. Note that the effect of moisture was accounted for in the models of wet triplets by considering the wet material properties of both bricks and mortars described in Section 2.1.1 and 2.1.2.

\subsubsection{Strengthening materials}

The fibre reinforced polymer (FRP) sheets were modelled with 4-nodded reduced integration membrane (M3D4R) elements. The interaction between triplets and FRP, assumed as full bonding, was modelled by means of a tie constraint to ensure that the nodes on the two surfaces displace simultaneously. The material characteristics of the FRP sheets were assigned as lamina. The elastic modulus and fracture strength in the direction of the fibres were those provided by the manufacturer as described in Section 2.1.3. As these laminates are unidirectional, the properties perpendicular to the direction of the fibres were given very small values. In contrast, the glass fibre mesh (GFM) is a bi-directional material with largely similar warp and weft properties. Additionally, the GFM strengthened specimens were provided with a lime mortar overlay. In order to simplify the model, both the GFM and mortar layer were modelled with a single membrane (M3D4R) element with homogenised properties [98]. A macro-modelling approach assuming a homogenised layer of render and mesh was considered [99]. The fibre grids were modelled as fully embedded in the render matrix and therefore a full compatibility and perfect bond between the two constituents exists. Although bond-slip between the composite matrix and the masonry substrate can be incorporated in the model, this was not considered for the simulations in this paper as this procedure is associated with high computational costs. The composite material was modelled as lamina to represent its response as an orthotropic material in plane stress [88, 100]. With the lack of 
experimental data, the tensile properties of the composite were considered as those provided by the manufacturer for the mesh in tension, whilst the compression render properties were considered as obtained from material tests. Although this provides an approximate estimate of the properties of the composite, these values would be expected to offer lower bound predictions of the actual behaviour.

\subsubsection{Numerical procedures}

A three-step numerical analysis was carried out to simulate the test response described in Section 3. The initial step included the definition of the boundary conditions and cohesive interface properties as well as a multi-point tie constraint between a reference point and central brick (Figure 9b-d). Several modelling procedures were considered regarding the interface behaviour at the boundary conditions. Besides the model details illustrated in Figure 9, in which the boundary conditions were assigned directly to the bottom brick, a case in which the steel blocks (supports) were modelled, was considered. This included node-to-surface interaction properties between the bricks and steel blocks. These were assigned with 'hard contact' properties following the normal direction and a 'penalty' friction formulation $(\mu=0.5)$ following the tangential direction. For this particular case, there was no influence from the modelling procedures in terms of load-shear displacement response, and the simplified modelling approach in which the boundary conditions were applied directly to the bricks, was considered for all models. In the following step, a pre-compression stress $\sigma_{\mathrm{c}}$ was applied whilst all properties assigned in the initial step were propagated. In the last step, a vertical displacement $\delta$ was applied to the central brick through the reference point, whilst the $\sigma_{\mathrm{c}}$ was maintained. In both cases, the actions (load or stress) were incrementally imposed by means of a Newton-Raphson integration procedure with large displacement non-linear geometry effects considered. It is worth noting that in terms of interface response, the normal-direction behaviour is activated only when the cohesive bond becomes fully damaged, and cohesive surfaces do not undergo damage under pure compression.

\subsection{Numerical results}

All triplet configurations were modelled and, for compactness, selected results of wet nonstrengthened (Specimens TW), FRP and GFM strengthened triplets (Specimens TFH and TTA, respectively) are comparatively presented against the corresponding dry non-strengthened counterparts (Specimens TD). The numerical simulations of the load and shear stress - shear displacement $\left(\mathrm{P}-\delta_{\mathrm{s}}\right.$ and $\left.\tau-\delta_{\mathrm{s}}\right)$ relationships compared with the corresponding test results are shown in Figure 11. The elastic shear stiffness, nominal shear stress/strength $\tau_{\mathrm{m}}$ and corresponding initial 
shear sliding $\delta_{\mathrm{s}}{ }^{0}$ are relatively well predicted for all configurations, regardless of the precompression level $\sigma_{\mathrm{c}}$. Importantly, the energy-based modelling approach of the cohesive surface damage produced representative results. Although a linear representation was chosen, as described above, the numerical post-peak softening $\tau-\delta_{\mathrm{s}}$ response is in close agreement with the corresponding test curve which would be represented by an exponential decay function.

As mentioned above, the response of the FRP strengthened triplets was generally governed by the fracture properties of the bricks which determine the ultimate response. As shown in Figure 6c,d and 7c,d, the FRP-to-brick surface adhesion was stronger than the tensile capacity of the bricks, hence failure occurred due to brick cracking. This is well captured by the employed modelling procedures, both at the constitutive $\tau-\delta_{\mathrm{s}}$ response and through the tension damage patterns illustrated in each panel of Figure 11 corresponding to FRP-strengthened specimens. Instead of a gradual softening as obtained for the GFM-strengthened models, also in good agreement with tests, the $\tau$ - $\delta_{\mathrm{s}}$ of triplet models with FRP laminates show a more sudden drop in shear stress after $\tau_{\mathrm{m}}$ is reached. Overall, the deformational response and failure modes obtained from the numerical simulations were in good agreement with reported tests results.

As shown by the shear stress - slip curves in Figure 5a,b and the shear strength-to-precompression relationships in Figure 10a, the adhesion between lime mortar and clay bricks depended on the moisture conditions. As indicated by the constitutive response in Figure 1b, wet mortars had lower stiffness and strength than ambient-dry mortars. Hence, at high precompression levels, the wet-todry shear strength ratio was generally lower than that at low precompression (Figure 10a). These results offer valuable insight into the performance of wet masonry and can be directly employed in structural assessment and safety evaluation of existing heritage structures [46].

Figures $5 \mathrm{c}-\mathrm{f}$ and Figure $10 \mathrm{~b}$ provide fundamental insights into the interfacial behaviour of strengthened triplets and inform possible strengthening strategies of heritage structures. It is shown that the shear capacity and ductility of the specimens varies with the characteristics of the strengthening system utilised. Although flexible mesh systems with mortar overlays (TTA/TTB Specimens) offered limited strength enhancement, they were more ductile than fibre reinforced polymer laminates (TFH/TFD Specimens). Full-field measurements of in-plane shear behaviour showed that although both strengthening techniques have their merits (i.e. FRP provides higher strength but lower ductility, while GFM provides lower strength but higher ductility), flexible meshes are a better alternative. These are also typically more compatible with masonry substrate $[21,45]$. The above comment is primarily related to the compatibility between the strengthening 
system and masonry substrate. For the brick material strengths from this paper, in FRP-strengthened triplets, failure typically occurred due to fracture of the brick with very limited utilisation of the FRP laminate. On the other hand, when GFM with render was provided, the fibres were activated progressively and contributed to triplet strength, resulting in similar overall performance to that obtained in FRP-strengthened cases.

The tests provided detailed information on the mechanical behaviour of triplets under ambient-dry and wet conditions, as well as the effectiveness of the employed strengthening techniques. Importantly, the main response parameters obtained from the tests were also used to determine masonry interface coefficients such as the cohesion and the internal friction angle as well as the inplane shear fracture energy. As one of the objectives of the research programme is to offer detailed safety evaluation of heritage structures using non-linear computational models, these parameters can be used for modelling the interface behaviour of masonry joints. Although the aim of this study was the shear response and interface properties of lime mortar - clay brick masonry, the behaviour and main interface parameters examined would also be relevant to other type of masonry with similar mechanical properties.

\section{Concluding remarks}

This paper presented an experimental programme into the fundamental shear response of masonry triplets incorporating fired-clay bricks and hydraulic lime mortars under ambient-dry and wet conditions, as well as strengthened specimens with fibre reinforced polymer (FRP) laminates and glass fibre mesh (GFM). After describing the materials, mix designs and specimen details, the main test results and key observations resulting from detailed test measurements were reported. Moreover, comparative assessments in terms of expansion to shear displacement response of the brick-mortar interfaces were performed. Complementary nonlinear simulations were undertaken, and numerical validations in terms of shear stiffness, shear strength and in-plane shear fracture energy against representative test configurations were carried out. Based on the results in this paper, several main conclusions can be drawn as discussed below.

Shear triplet tests on non-strengthened specimens showed that for specimens without precompression the failure was characterised by specimen separation into two distinct bodies, with the shear stress dropping instantaneously. On the other hand, for tests with pre-compression, failure occurred at the brick-mortar interface and propagated through the mortar layer. Moreover, the mortar from dry specimens had less cohesion, breaking in multiple lumps, whilst the mortar from 
wet specimens had fewer fracture surfaces due to paste-like consistency. For all pre-compression levels, the wet triplets had a lower strength than those in dry conditions.

Specimens provided with fibre reinforced polymer FRP sheets exhibited a higher strength enhancement than those with glass fibre mesh (GFM) for pre-compression stresses above zero. The strength increase provided by FRP was in the range of $16.6-185.8 \%$, depending on the laminate layout, whilst for GFM and mortar overlay together was less than 10\% on average, in comparison to non-strengthened dry counterpart. A significantly higher contribution from both FRP and GFM systems was observed for strengthened elements without pre-compression for which the strength was higher at least by a factor of eight and five, respectively. In these cases, both systems proved to be effective in restricting brick-mortar interface separation and maintaining specimen integrity.

For FRP-strengthened triplets, the failure was governed by the brick and mortar tensile properties rather than that of FRPs due to their relative high strength. Due to brick material brittleness, the shear stress - shear displacement of triplets with FRP showed a more sudden drop in stress after the peak was reached, in comparison to GFM-strengthened triplets. The latter developed a more gradual post-peak softening. Unsurprisingly, limited contribution was obtained from the FRP as the strain levels on the sheet surface were less than $10 \%$ of the ultimate material strain, whilst GFM was gradually and fully activated. Although the strength increase due to the presence of GFM was modest, the post-peak performance was more favourable, with a more gradual stress reduction with the increase in slip. Due to the relatively low strength combined with high elongation properties, GFM seems to be a better alternative when ductility is sought as this is activated gradually and leads to a relatively ductile interface behaviour. In contrast, when strength enhancement is the main consideration, FRP materials offer a possible solution.

Numerical models employing surface-based cohesive-contact approaches with due account for inelastic damage for modelling masonry interfaces, and damage-plasticity models to represent the constitutive behaviour of brick materials, were shown to be able to capture the main behavioural characteristics such as elastic shear stiffness, shear strength, post-peak response as well as failure modes through the obtained tension damage patterns. Such numerical procedures, which are calibrated and validated using the test results presented in this study, can be employed for detailed modelling of masonry components of similar mechanical properties to those investigated in this paper. Overall, the experimental observations and numerical procedures employed offer guidance on the selection of possible strengthening techniques for heritage masonry, within the material geometric ranges considered in this investigation. 


\section{Compliance with ethical standards:}

Funding: The study was supported by the Arts and Humanities Research Council of the UK Research and Innovation agency, within the project "Interdisciplinary approach for the management and conservation of UNESCO World Heritage Site of Historic Cairo - Application to Al-Ashraf Street", Grant No. AH/R00787X/1.

Conflict of interest: The authors declare that they have no conflict of interest.

Credit author statement: D.V. Bompa: Conceptualization, Methodology, Investigation, Formal analysis, Writing - Original Draft; A.Y. Elghazouli: Conceptualization, Funding Acquisition, Writing Review \& Editing.

Acknowledgements: The authors would like to acknowledge the support provided by the technical staff of the Structures Laboratories at Imperial College London.

\section{References}

[1] Cotic, P., Jaglicic, Z., Niederleithinger, E., Effner, U., Kruschwitz, S., Trela, C. and Bosiljkov, V., 2013. Effect of moisture on the reliability of void detection in brickwork masonry using radar, ultrasonic and complex resistivity tomography. Materials and structures, 46(10), 1723-1735. https://doi.org/10.1617/s11527-012-0011-3

[2] Gentilini, C., Franzoni, E., Graziani, G. and Bandini, S., 2015. Mechanical properties of fired-clay brick masonry models in moist and dry conditions. In Key Engineering Materials, 624, 307-312. Trans Tech Publications Ltd. https://doi.org/10.4028/www.scientific.net/KEM.624.307

[3] Giaccone, D., Santamaria, U. and Corradi, M., 2020. An Experimental Study on the Effect of Water on Historic Brickwork Masonry. Heritage, 3(1), 29-46. https://doi.org/10.3390/heritage3010003

[4] Walker, R., Pavía, S. and Dalton, M., 2016. Measurement of moisture content in solid brick walls using timber dowel. Materials and Structures, 49(7), 2549-2561. https://doi.org/10.1617/s11527-015-0667-6

[5] Maheri, M.R. and Sherafati, M.A., 2012. The effects of humidity and other environmental parameters on the shear strength of brick walls: evaluation of field test data. Materials and structures, 45(6), 941-956. https://doi.org/10.1617/s11527-011-9809-7

[6] Aubert, J.E., Maillard, P., Morel, J.C. and Al Rafii, M., 2016. Towards a simple compressive strength test for earth bricks?. Materials and Structures, 49(5), 1641-1654.https://doi.org/10.1617/s11527-015-0601-y

[7] Guizzardi, M., Derome, D., Mannes, D., Vonbank, R. and Carmeliet, J., 2016. Electrical conductivity sensors for water penetration monitoring in building masonry materials. Materials and Structures, 49(7), 2535-2547. https://doi.org/10.1617/s11527-015-0666-7

[8] Tomazevic, M., Weiss, P. and Lutman, M., 1994. Influence of floors and connection of walls on seismic resistance of old brick masonry buildings. Institute for testing and research in materials and structures, ZAG, Ljubijana.

[9] Giuriani, E. and Marini, A., 2008. Wooden roof box structure for the anti-seismic strengthening of historic buildings. International Journal of Architectural Heritage, 2(3), 226-246. https://doi.org/10.1080/15583050802063733

[10] Messali, F., Metelli, G. and Plizzari, G., 2017. Experimental results on the retrofitting of hollow brick masonry walls with reinforced high performance mortar coatings. Construction and building materials, 141, 619-630. https://doi.org/10.1016/j.conbuildmat.2017.03.112

[11] Franzoni, E., Gentilini, C., Graziani, G. and Bandini, S., 2014. Towards the assessment of the shear behaviour of masonry in on-site conditions: A study on dry and salt/water conditioned brick masonry triplets. Construction and Building Materials, 65, 405-416. https://doi.org/10.1016/j.conbuildmat.2014.05.002

[12] Mazzotti, C., Sassoni, E. and Pagliai, G., 2014. Determination of shear strength of historic masonries by moderately destructive testing of masonry cores. Construction and Building Materials, 54, 421-431. https://doi.org/10.1016/j.conbuildmat.2013.12.039 
[13] Franzoni, E., Gentilini, C., Graziani, G. and Bandini, S., 2015. Compressive behaviour of brick masonry triplets in wet and dry conditions. Construction and Building Materials, 82, 45-52.

https://doi.org/10.1016/j.conbuildmat.2015.02.052

[14] Bompa D.V, Elghazouli A.Y, 2020. Compressive behaviour of fired-clay brick and lime mortar masonry components in dry and wet conditions. Materials and Structures 53, 60 (2020). https://doi.org/10.1617/s11527020-01493-w

[15] Mayorca, P. and Meguro, K., 2004, August. Proposal of an efficient technique for retrofitting unreinforced masonry dwellings. In 13th World Conference on Earthquake Engineering (No. 2431). http://www.iitk.ac.in/nicee/wcee/article/13 2431.pdf

[16] Fossetti, M. and Minafò, G., 2017. Comparative experimental analysis on the compressive behaviour of masonry columns strengthened by FRP, BFRCM or steel wires. Composites Part B: Engineering, 112, 112-124. https://doi.org/10.1016/j.compositesb.2016.12.048

[17] Liu, K., Wang, M. and Wang, Y., 2015. Seismic retrofitting of rural rammed earth buildings using externally bonded fibers. Construction and Building Materials, 100, 91-101.

https://doi.org/10.1016/j.conbuildmat.2015.09.048

[18] Buchan, P.A. and Chen, J.F., 2007. Blast resistance of FRP composites and polymer strengthened concrete and masonry structures-A state-of-the-art review. Composites Part B: Engineering, 38(5-6), 509-522. https://doi.org/10.1016/j.compositesb.2006.07.009

[19] Tumialan, J.G., Micelli, F. and Nanni, A., 2001. Strengthening of masonry structures with FRP composites. In Structures 2001: A Structural Engineering Odyssey, 1-8. https://doi.org/10.1061/40558(2001)130

[20] Righetti, L., Edmondson, V., Corradi, M. and Borri, A., 2016. Fiberglass grids as sustainable reinforcement of historic masonry. Materials, 9(7), p.603. https://doi.org/10.3390/ma9070603

[21] Koutas, L., Bousias, S.N. and Triantafillou, T.C., 2014. Seismic strengthening of masonry-infilled RC frames with TRM: Experimental study. Journal of Composites for Construction, 19(2), p.04014048. https://doi.org/10.1061/(ASCE)CC.1943-5614.0000507

[22] Hamid, A.A., El-Dakhakhni, W.W., Hakam, Z.H. and Elgaaly, M., 2005. Behavior of composite unreinforced masonry-fiber-reinforced polymer wall assemblages under in-plane loading. Journal of Composites for Construction, 9(1), 73-83. https://doi.org/10.1061/(ASCE)1090-0268(2005)9:1(73)

[23] Borri, A., Castori, G., Corradi, M. and Speranzini, E., 2011. Shear behavior of unreinforced and reinforced masonry panels subjected to in situ diagonal compression tests. Construction and Building Materials, 25(12), 4403-4414. https://doi.org/10.1016/j.conbuildmat.2011.01.009

[24] Wang, Y., Wang, M., Liu, K., Pan, W. and Yang, X., 2017. Shaking table tests on seismic retrofitting of rammed-earth structures. Bulletin of Earthquake Engineering, 15(3), 1037-1055.

https://doi.org/10.1007/s10518-016-9996-2

[25] Mustafaraj, E. and Yardim, Y., 2019. Retrofitting damaged unreinforced masonry using external shear strengthening techniques. Journal of Building Engineering, 26, p.100913.

https://doi.org/10.1016/j.jobe.2019.100913

[26] Krevaikas, T.D. and Triantafillou, T.C., 2005. Masonry confinement with fiber-reinforced polymers. Journal of composites for construction, 9(2), 128-135.

[27] Ehsani, M.R., Saadatmanesh, H. and Al-Saidy, A., 1997. Shear behavior of URM retrofitted with FRP overlays. Journal of composites for construction, 1(1), 17-25. https://doi.org/10.1061/(ASCE)10900268(1997)1:1(17)

[28] Luccioni, B. and Rougier, V.C., 2011. In-plane retrofitting of masonry panels with fibre reinforced composite materials. Construction and Building Materials, 25(4), 1772-1788. https://doi.org/10.1016/j.conbuildmat.2010.11.088

[29] Valluzzi, M.R., Tinazzi, D. and Modena, C., 2002. Shear behavior of masonry panels strengthened by FRP laminates. Construction and Building materials, 16(7), 409-416. https://doi.org/10.1016/S0950-0618(02)00043-0

[30] El-Diasity, M., Okail, H., Kamal, O. and Said, M., 2015. Structural performance of confined masonry walls retrofitted using ferrocement and GFRP under in-plane cyclic loading. Engineering Structures, 94, 54-69. https://doi.org/10.1016/j.engstruct.2015.03.035

[31] Ismail, N. and Ingham, J.M., 2014. Polymer textiles as a retrofit material for masonry walls. Proceedings of the Institution of Civil Engineers-Structures and Buildings, 167(1), 15-25. https://doi.org/10.1680/stbu.11.00084 
[32] Messali, F., Metelli, G. and Plizzari, G., 2017. Experimental results on the retrofitting of hollow brick masonry walls with reinforced high-performance mortar coatings. Construction and Building Materials, 141, 619-630. https://doi.org/10.1016/j.conbuildmat.2017.03.112

[33] Papanicolaou, C., Triantafillou, T. and Lekka, M., 2011. Externally bonded grids as strengthening and seismic retrofitting materials of masonry panels. Construction and Building Materials, 25(2), 504-514. https://doi.org/10.1016/j.conbuildmat.2010.07.018

[34] Bilotta, A., Ceroni, F., Nigro, E. and Pecce, M., 2017. Experimental tests on FRCM strengthening systems for tuff masonry elements. Construction and Building Materials, 138, 114-133.

https://doi.org/10.1016/j.conbuildmat.2017.01.124

[35] Oskouei, A.V., Jafari, A., Bazli, M. and Ghahri, R., 2018. Effect of different retrofitting techniques on in-plane behavior of masonry wallettes. Construction and Building Materials, 169, 578-590.

https://doi.org/10.1016/j.conbuildmat.2018.02.197

[36] Chourasia, A., Singhal, S. and Parashar, J., 2019. Experimental investigation of seismic strengthening technique for confined masonry buildings. Journal of Building Engineering, p.100834.

https://doi.org/10.1016/j.jobe.2019.100834

[37] Blondet, M., Torrealva, D., Vargas, J., Velasquez, J. and Tarque, N., 2006, September. Seismic reinforcement of adobe houses using external polymer mesh. In First European Conference on Earthquake Engineering and Seismology. Geneva, Switzerland.

[38] Manzoni, E., Dusi, A. and Mezzi, M., 2008, October. Polymeric grid for a cost effective enhancement of the seismic performance of masonry buildings. In 14th World Conference on Earthquake Engineering, Beijing, China. ftp://jetty.ecn.purdue.edu/spujol/Andres/files/S11-008.PDF

[39] Bompa, D.V., Elghazouli, A.Y., 2020. Properties of hydraulic lime mortars subjected to dry-wet cycles. Technical report, Imperial College London, UK.

[40] Alecci, V., Fagone, M., Rotunno, T. and De Stefano, M., 2013. Shear strength of brick masonry walls assembled with different types of mortar. Construction and Building Materials, 40, 1038-1045.

https://doi.org/10.1016/j.conbuildmat.2012.11.107

[41] Corinaldesi, V., 2012. Environmentally-friendly bedding mortars for repair of historical buildings. Construction and Building Materials, 35, 778-784. https://doi.org/10.1016/j.conbuildmat.2012.04.131

[42] Zhou, Z., Walker, P. and D'Ayala, D., 2008. Strength characteristics of hydraulic lime mortared brickwork. Proceedings of the Institution of Civil Engineers-Construction Materials, 161(4), 139-146. https://doi.org/10.1680/coma.2008.161.4.139

[43] Pelà, L., Kasioumi, K. and Roca, P., 2017. Experimental evaluation of the shear strength of aerial lime mortar brickwork by standard tests on triplets and non-standard tests on core samples. Engineering Structures, 136, 441453. https://doi.org/10.1016/j.engstruct.2017.01.028

[44] Zimmermann, T., Strauss, A. and Bergmeister, K., 2012. Structural behavior of low-and normal-strength interface mortar of masonry. Materials and structures, 45(6), 829-839. https://doi.org/10.1617/s11527-011-98012

[45] Giaretton, M., Dizhur, D., Garbin, E., Ingham, J.M. and da Porto, F., 2018. In-plane strengthening of clay brick and block masonry walls using textile-reinforced mortar. Journal of Composites for Construction, 22(5), p.04018028. https://doi.org/10.1061/(ASCE)CC.1943-5614.0000866

[46] Luccioni, B. and Rougier, V.C., 2010. Shear behaviour of brick-mortar interface in CFRP retrofitted or repaired masonry. International journal of mechanical sciences, 52(4), 602-611. https://doi.org/10.1016/j.ijmecsci.2009.12.009

[47] Roca, P. and Araiza, G., 2010. Shear response of brick masonry small assemblages strengthened with bonded FRP laminates for in-plane reinforcement. Construction and Building Materials, 24(8), 1372-1384. https://doi.org/10.1016/j.conbuildmat.2010.01.005

[48] Livitsanos, G., Shetty, N., Verstrynge, E., Wevers, M., Van Hemelrijck, D. and Aggelis, D.G., 2019. Shear failure characterization in masonry components made with different mortars based on combined NDT methods. Construction and Building Materials, 220, 690-700. https://doi.org/10.1016/j.conbuildmat.2019.06.058

[49] Caggegi, C., Chevalier, L., Pensée, V. and Cuomo, M., 2016. Strain and shear stress fields analysis by means of Digital Image Correlation on CFRP to brick bonded joints fastened by fiber anchors. Construction and Building Materials, 106, 78-88. https://doi.org/10.1016/j.conbuildmat.2015.12.089 
[50] Ghiassi, B., Xavier, J., Oliveira, D.V., Kwiecien, A., Lourenço, P.B. and Zajac, B., 2015. Evaluation of the bond performance in FRP-brick components re-bonded after initial delamination. Composite Structures, 123, 271281. https://doi.org/10.1016/j.compstruct.2014.12.047

[51] D’Altri, A.M., Sarhosis, V., Milani, G., Rots, J., Cattari, S., Lagomarsino, S., Sacco, E., Tralli, A., Castellazzi, G. and de Miranda, S., 2019. Modeling strategies for the computational analysis of unreinforced Masonry structures: Review and classification. Archives of Computational Methods in Engineering, 1-33. https://doi.org/10.1007/s11831-019-09351-x

[52] Elghazouli A., Butler A., Mourad S., Cheeseman C., Elyamani A, 2018, Interdisciplinary approach for the management and conservation of UNESCO World Heritage Site of Historic Cairo. Application to Al-Ashraf Street. UK Research and Innovation, viewed 7 July 2019, https://gtr.ukri.org/projects?ref=AH\%2FR00787X\%2F1

[53] BS EN 459-2. Building lime: test methods. British Standards Institution, UK.

[54] Secil Argamassas, Natural hydraulic lime (NHL) - the binder. Available at: https://www.secilargamassas.pt/uploads/documentos/Ficha_Tecnica_NHL_5.pdf [accessed 10 November 2019]

[55] Ince, C., Carter, M.A. and Wilson, M.A., 2015. The water retaining characteristics of lime mortar. Materials and Structures, 48(4), 1177-1185. https://doi.org/10.1617/s11527-013-0224-0

[56] BS EN 13139:2013 Aggregates for mortar. British Standards Institution, UK.

[57] Flower, D.J. and Sanjayan, J.G., 2007. Green house gas emissions due to concrete manufacture. The international Journal of life cycle assessment, 12(5), p.282. https://doi.org/10.1065/lca2007.05.327

[58] BS EN 933-1:2012. Tests for Geometrical Properties of Aggregates Part 1: Determination of Particle Size Distribution-Sieving Method. British Standards Institution, UK.

[59] BS EN 1015-2: Methods of test for mortar for masonry-Part 2: Bulk sampling of mortars and preparation of test mortars. British Standards Institution, UK

[60] BS EN 1015-3:1999 Methods of test for mortar for masonry — Part 3: Determination of consistence of fresh mortar (by flow table). British Standards Institution, UK.

[61] BS EN 1015-11:1999 Methods of test for mortar for masonry - Part 11: Determination of flexural and compressive strength of hardened mortar. British Standards Institution, UK

[62] Faria, P., Henriques, F. and Rato, V., 2008. Comparative evaluation of lime mortars for architectural conservation. Journal of Cultural Heritage, 9(3), 338-346. https://doi.org/10.1016/j.culher.2008.03.003

[63] Maravelaki-Kalaitzaki, P., Bakolas, A., Karatasios, I. and Kilikoglou, V., 2005. Hydraulic lime mortars for the restoration of historic masonry in Crete. Cement and Concrete Research, 35(8), 1577-1586. https://doi.org/10.1016/j.cemconres.2004.09.001

[64] Grilo, J., Faria, P., Veiga, R., Silva, A.S., Silva, V. and Velosa, A., 2014. New natural hydraulic lime mortarsphysical and microstructural properties in different curing conditions. Construction and Building Materials, 54, 378-384. https://doi.org/10.1016/j.conbuildmat.2013.12.078

[65] Egernsund Tegl, Chelmer Red Imperial. Available at: https://www.egernsund-tegl.com/products/bricks/2702.2.07-chelmer-red-imperial [accessed 10 November 2019]

[66] BS EN 771-1:2011+A1:2015. Specification for masonry units Part 1: Clay masonry units. British Standards Institution, UK.

[67] Saint-Gobain Weber, 2016. Webertec force EP bonding adhesive. [Online] Available from: https://www.uk.weber/files/gb/2018-03/10.060_webertec_force_EP_bonding_adhesive.pdf (accessed 25.02.19).

[68] Saint-Gobain Weber, 2016. Webertec force aramid sheet. [Online] Available from: https://www.uk.weber/files/gb/2018-03/10.025_webertec_force_aramid_sheet.pdf (accessed 25.2.19).

[69] Ceresit CT 325 TT160 Glass-Fibre Mesh - Reinforcing mesh for Ceresit Ceretherm External Thermal Insulation Composite Systems https://www.ceresit.com/content/dam/uac/ceresit/master/TDS-Documents/Etics/newtds/CT325_TDS.pdf (accessed 16.4.20)

[70] Sathiparan, N. and Rumeshkumar, U., 2018. Effect of moisture condition on mechanical behavior of low strength brick masonry. Journal of Building Engineering, 17, 23-31. https://doi.org/10.1016/j.jobe.2018.01.015

[71] Witzany, J., Cejka, T. and Zigler, R., 2010. The effect of moisture on significant mechanical characteristics of masonry. Statybines Konstrukcijos ir Technologijos, 2(3), 79-85

[72] Tomaževič, M., 2009. Shear resistance of masonry walls and Eurocode 6: shear versus tensile strength of masonry. Materials and structures, 42(7), 889-907. https://doi.org/10.1617/s11527-008-9430-6 
[73] Zhang, S., Richart, N. and Beyer, K., 2018. Numerical evaluation of test setups for determining the shear strength of masonry. Materials and Structures, 51(4), p.110. https://doi.org/10.1617/s11527-018-1236-6

[74] BS EN 1052-3:2002. Methods of test for masonry-Part, 3. British Standards Institution, UK.

[75] Ravula, M.B. and Subramaniam, K.V., 2017. Experimental investigation of compressive failure in masonry brick assemblages made with soft brick. Materials and Structures, 50(1), 19. https://doi.org/10.1617/s11527-016-09261

[76] Bompa, D.V. and Elghazouli, A.Y., 2018, November. Monotonic and cyclic performance of threaded reinforcement splices. Structures, 16, 358-372. https://doi.org/10.1016/j.istruc.2018.11.009

[77] LaVision - DaVis digital image correlation software http://www.lavision.de/en/products/davissoftware/index.php [accessed 10 November 2019]

[78] Sahu, S., Teja, P.R.R., Sarkar, P. and Davis, R., 2019. Effect of Brick Prewetting on Masonry Bond Strength. Journal of Materials in Civil Engineering, 31(10), p.06019009.

https://doi.org/10.1061/(ASCE)MT.1943-5533.0002866

[79] Gopalaratnam, V.S. and Gettu, R., 1995. On the characterization of flexural toughness in fiber reinforced concretes. Cement and concrete composites, 17(3), 239-254. https://doi.org/10.1016/0958-9465(95)99506-O

[80] ASTM C1609/C1609M - 12 Standard Test Method for Flexural Performance of Fiber-Reinforced Concrete (Using Beam with Third-Point Loading) ASTM International (2013)

[81] Barragan, B., Gettu, R., Agullo, L. and Zerbino, R., 2006. Shear failure of steel fiber-reinforced concrete based on push-off tests. ACI Materials Journal, 103(4), p.251.

[82] Xu, B., Bompa, D.V., Elghazouli, A.Y., Ruiz-Teran, A.M. and Stafford, P.J., 2018. Behaviour of rubberised concrete members in asymmetric shear tests. Construction and Building Materials, 159, 361-375. https://doi.org/10.1016/j.conbuildmat.2017.10.091

[83] Lourenco PB (1998) Experimental and numerical issues in the modelling of the mechanical behaviour of masonry. In: Roca P et al (eds) Structural analysis of historical constructions II. CIMNE, Barcelona, pp 57-91

[84] van der Pluijm R., 1999. Out-of-plane bending of masonry: behavior and strength. Ph.D. thesis, Eindhoven University of Technology, The Netherlands

[85] Bazant, Z.P., Gambarova P.G., 1980. Rough crack models in reinforced concrete. Journal of Structural Engineering ASCE 106(4):819-842

[86] Bompa, D.V. and Elghazouli, A.Y., 2015. Ultimate shear behaviour of hybrid reinforced concrete beam-to-steel column assemblages. Engineering Structures, 101, 318-336.

[87] Andreotti, G., Graziotti, F. and Magenes, G., 2019. Expansion of mortar joints in direct shear tests of masonry samples: implications on shear strength and experimental characterization of dilatancy. Materials and Structures, 52(4), p.64. https://doi.org/10.1617/s11527-019-1366-5

[88] DSS (Dassault Systèmes Simulia Corp). ABAQUS Analysis user's manual 6.14-2, DSS, Providence, RI, USA. 2014.

[89] Abdulla, K.F., Cunningham, L.S. and Gillie, M., 2017. Simulating masonry wall behaviour using a simplified micro-model approach. Engineering Structures, 151, 349-365. https://doi.org/10.1016/j.engstruct.2017.08.021

[90] D'Altri, A.M., Messali, F., Rots, J., Castellazzi, G. and de Miranda, S., 2019. A damaging block-based model for the analysis of the cyclic behaviour of full-scale masonry structures. Engineering Fracture Mechanics, 209, 423448. https://doi.org/10.1016/j.engfracmech.2018.11.046

[91] Rahgozar, A. and Hosseini, A., 2017. Experimental and numerical assessment of in-plane monotonic response of ancient mortar brick masonry. Construction and Building Materials, 155, 892-909. https://doi.org/10.1016/j.conbuildmat.2017.08.079

[92] Lourenço PB. Computational strategies for masonry structures. TU Delft: Delft University of Technology; 1996.

[93] Van Mier, J.G.M, Shah, S.P., Arnaud, M., Balayssac, J.P., Bascoul, A., Choi, S., Dasenbrock, D., Ferrara, G., French, C., Gobbi, M.E., Karihaloo, B.L., 1997. Strain-softening of concrete in uniaxial compression. Mater Struct 30(4):195-209. https://doi.org/10.1007/BF02486177

[94] Kotsovos, M.D., 1983. Effect of testing techniques on the post-ultimate behaviour of concrete in compression. Materiaux et construction 16(1):3-12. https://doi.org/10.1007/BF02474861

[95] Oliveira, D.V., Lourenco, P.B., Roca, P., 2006. Cyclic behaviour of stone and brick masonry under uniaxial compressive loading. Mater Struct 39(2):247-257. https://doi.org/10.1617/s11527-005-9050-3 
[96] Mohamad, G., Lourenço, P.B. and Roman, H.R., 2006. Poisson behaviour of bedding mortar under multiaxial stress state. International Masonry Conference, 7, London, 2006 - "7th International Masonry Conference".

[97] Ravula, M.B. and Subramaniam, K.V., 2017. Experimental investigation of compressive failure in masonry brick assemblages made with soft brick. Materials and Structures, 50(1), 19. https://doi.org/10.1617/s11527-016-09261

[98] Anthoine, A., 1995. Derivation of the in-plane elastic characteristics of masonry through homogenization theory. International journal of solids and structures, 32(2), 137-163. https://doi.org/10.1016/00207683(94)00140-R

[99] Wang, X., Ghiassi, B., Oliveira, D.V. and Lam, C.C., 2017. Modelling the nonlinear behaviour of masonry walls strengthened with textile reinforced mortars. Engineering Structures, 134, 11-24. https://doi.org/10.1016/j.engstruct.2016.12.029

[100] Al-Salloum, Y.A., Elsanadedy, H.M., Alsayed, S.H. and Iqbal, R.A., 2012. Experimental and numerical study for the shear strengthening of reinforced concrete beams using textile-reinforced mortar. Journal of Composites for Construction, 16(1), 74-90. https://doi.org/10.1061/(ASCE)CC.1943-5614.0000239 
Figures
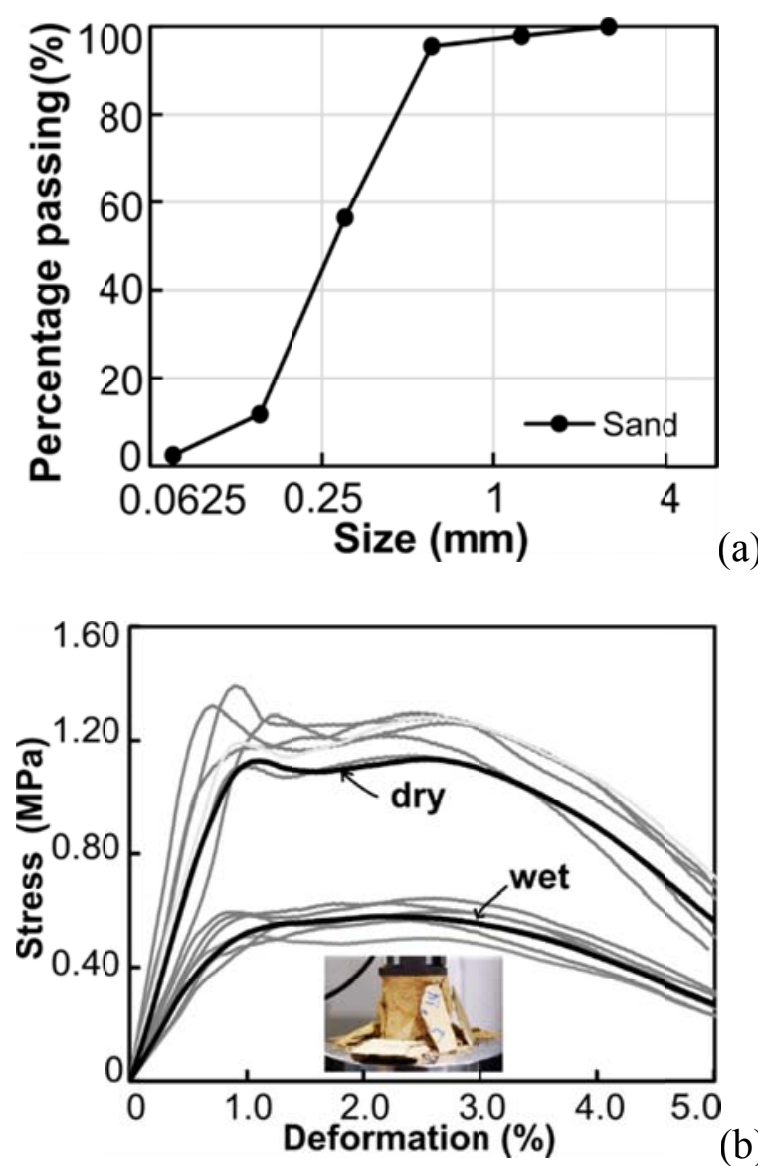

(b)

Figure 1 a) Sand gradation curve, b) mortar strengths non strengthened strengthened
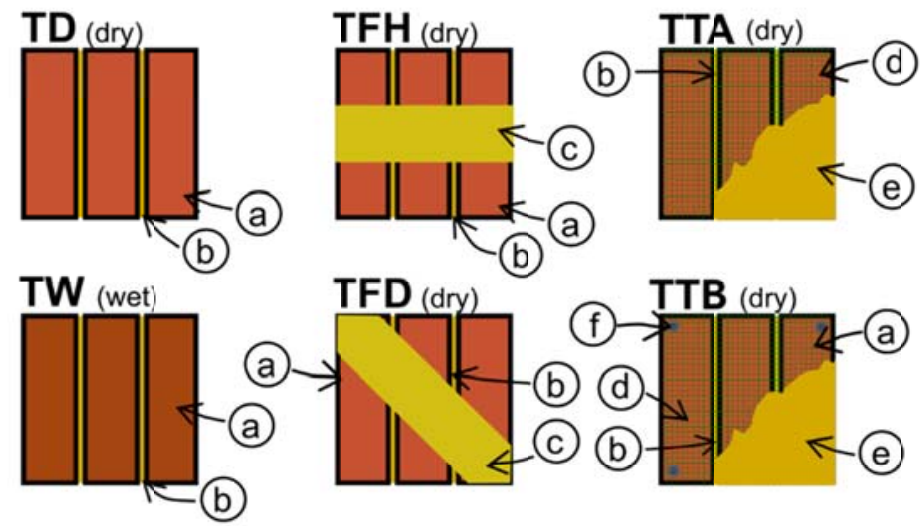
(a) bricks
(c) FRP sheets
(e) render
(b) mortar
(d) glass fibre mesh
(f) ties

Figure 2 Specimen details 


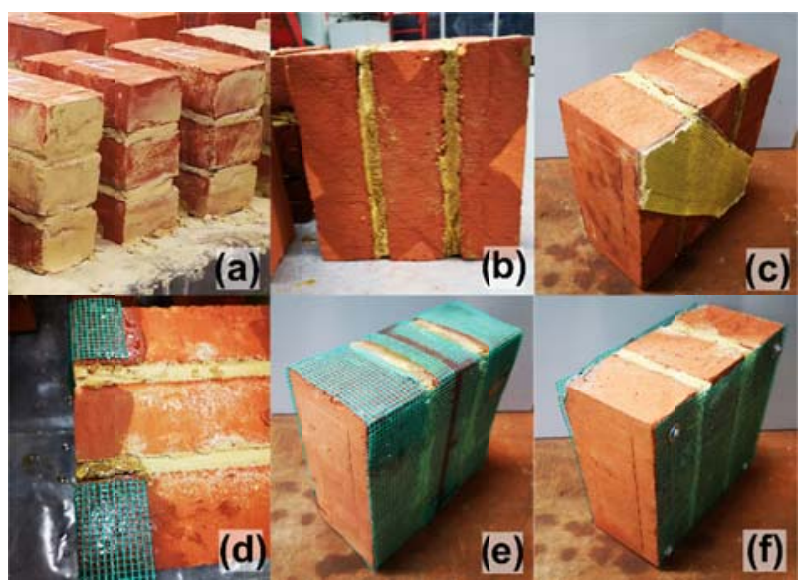

Figure 3 a) non-strengthened triplets, b) triplet after applying the primer, c) strengthened triplet with diagonal FRP sheets, d) epoxy bonding details of GFM, e) wrapped triplet with GFM, f) mechanically tied GFM..

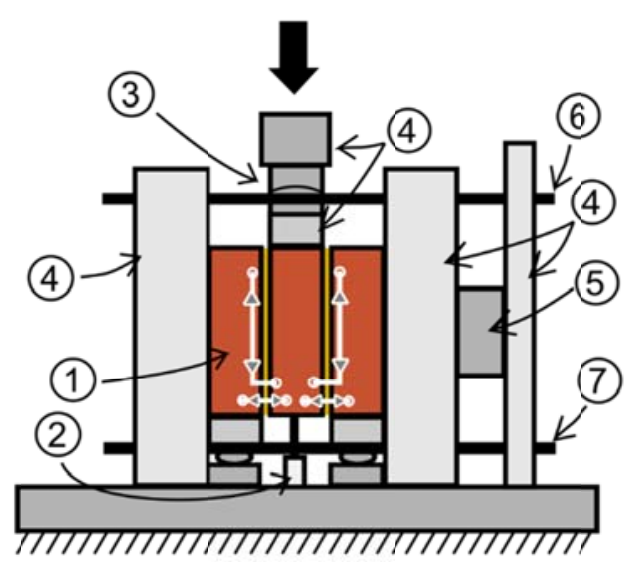

(1) specimen (2) transducers

(3) hinge (4) steel block/plate

(5) load cell (6) tie

Figure 4 Testing arrangement 



Figure 5 Shear stress - slip $\left(\tau-\delta_{s}\right)$ curves for non-strengthened specimens: a) dry TD specimens, b) wet $T W$ specimens; and strengthened specimens with: FRP laminates: c) horizontal sheets (TFH), d) diagonal sheets (TFD); with glass fibre mesh (GFM) and lime mortar render: e) resin bonded mesh (TTA), f) mechanically tied mesh (TTB) 

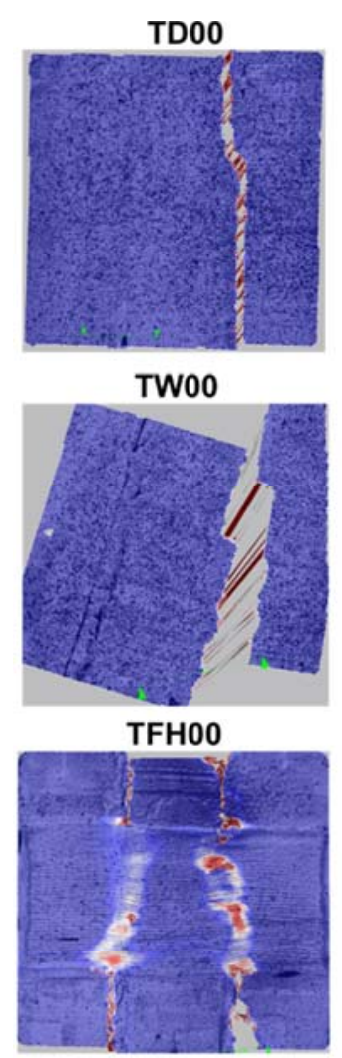

TFD00
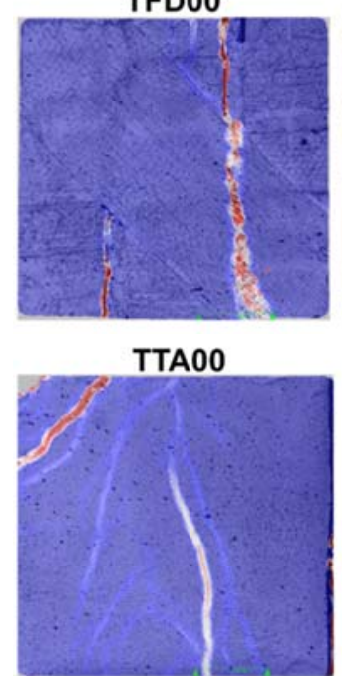

TTB00

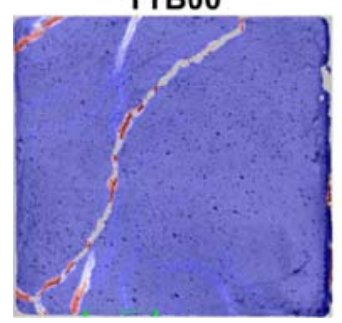

TD02

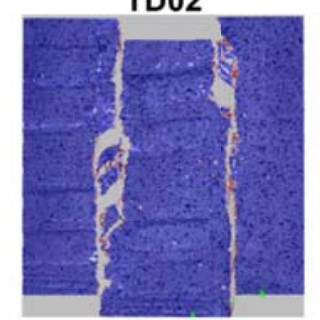

TW02

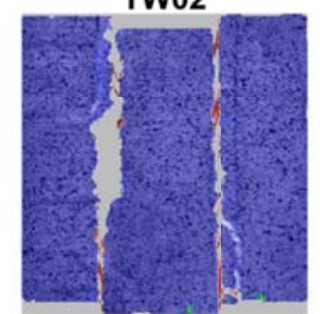

TFHO2

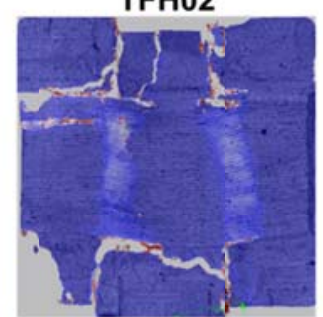

TFD02


TTB02

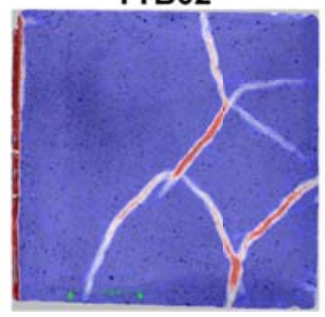

TD05

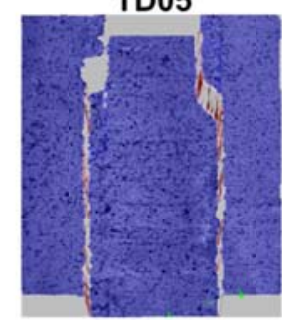

TW05

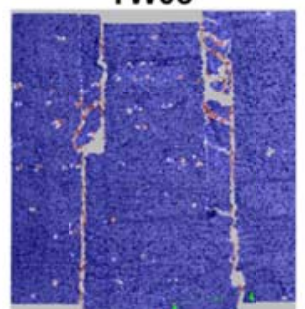

TFH05

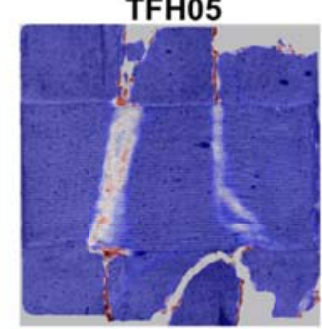

TFD05

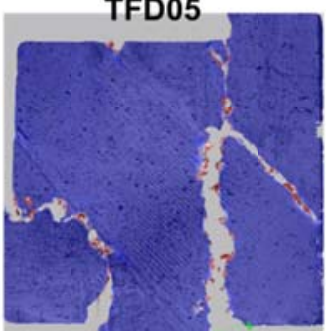

TTA05

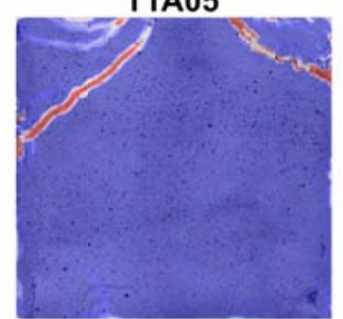

TTB05



TD10

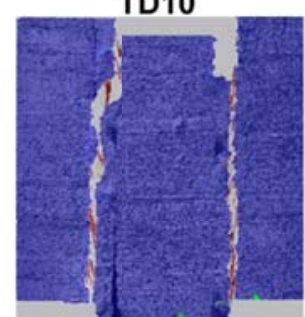

TW10



TFH10

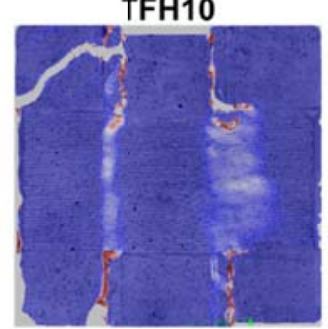

TFD10

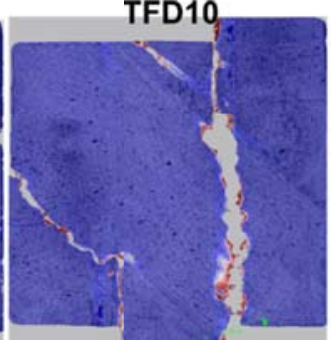

TTA10

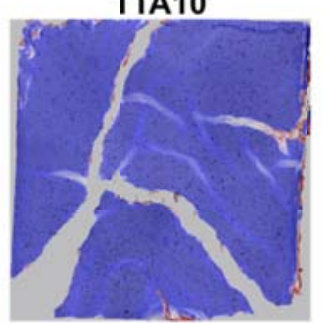

TTB10

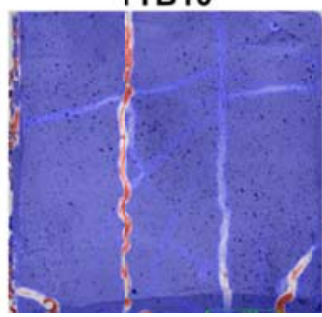

TD15

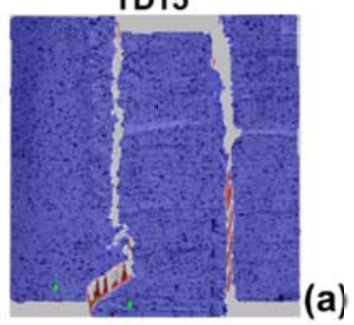

TW15

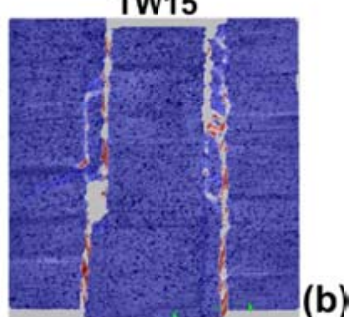

TFH15

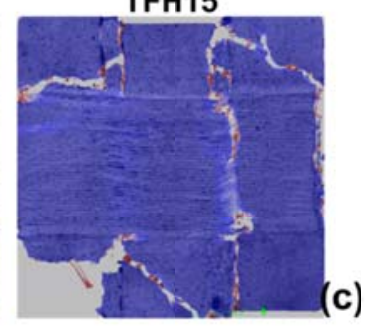

TFD15

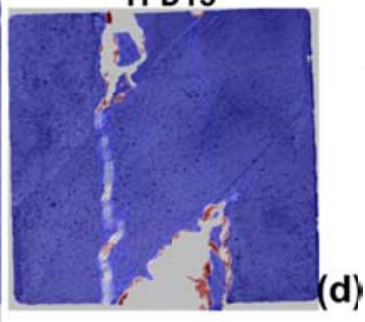

TTA15



TTB15

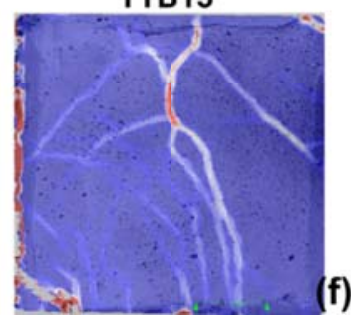

Figure 6 Specific post-peak crack pattens for Specimens a) TD, b) $T W$, c) $T F H$, d) $T F D$, e) $T T A, f) T T B$ 

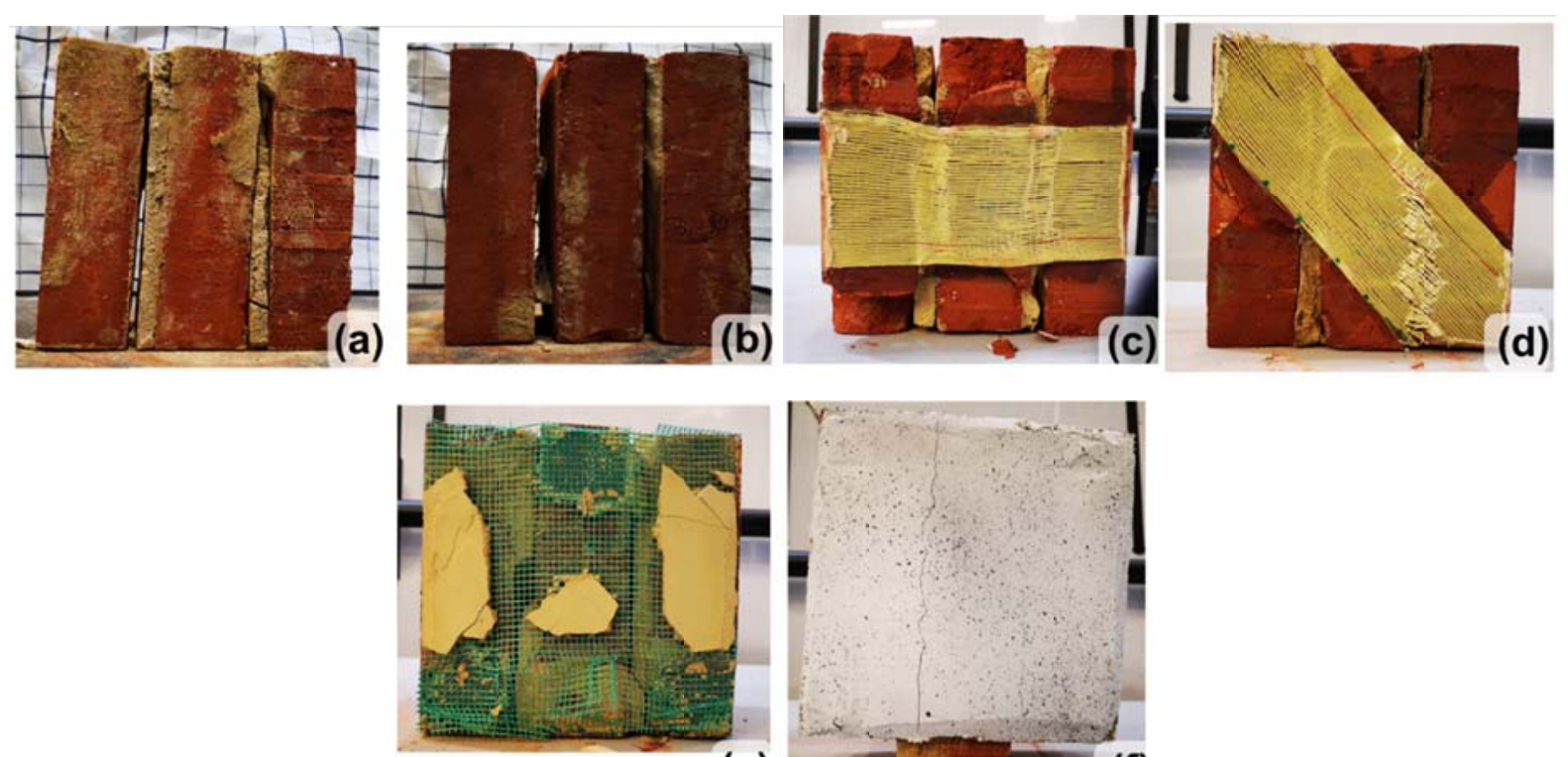

(e)

(f)

Figure 7 Characteristic failure modes of Specimens: a) TD, b)TW, c) TFH, d) TFD, e) TTA, f) TTB
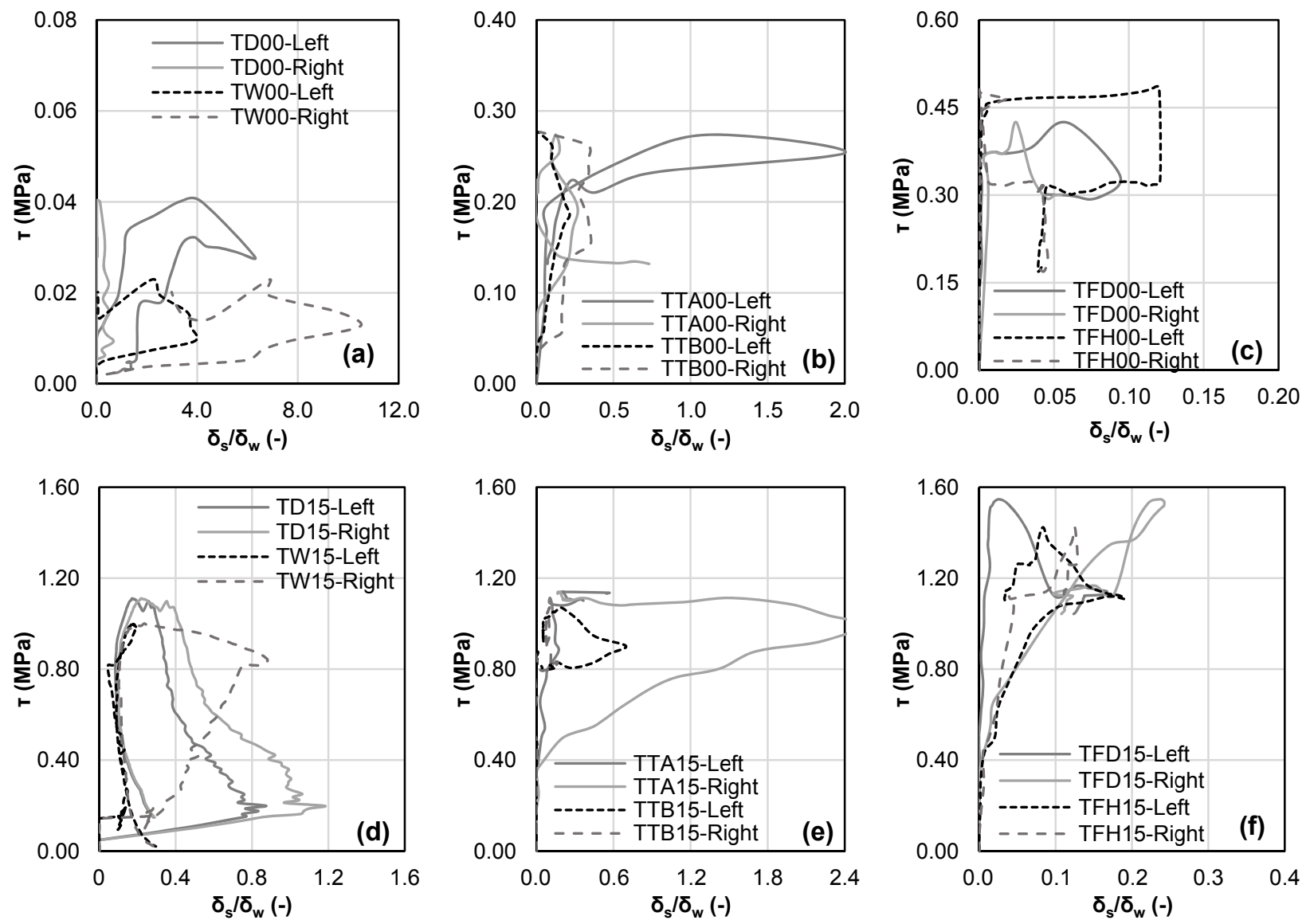

Figure 8 Dilation response of the tested specimens: $\sigma_{c}=0$ MPa a) TD vs TW, b) TTA vs TTB, c) TFH vs TFD; $\sigma_{c}=1.5$

MPa d) TD vs TW, e) TTA vs TTB, f) TFH vs TFD 

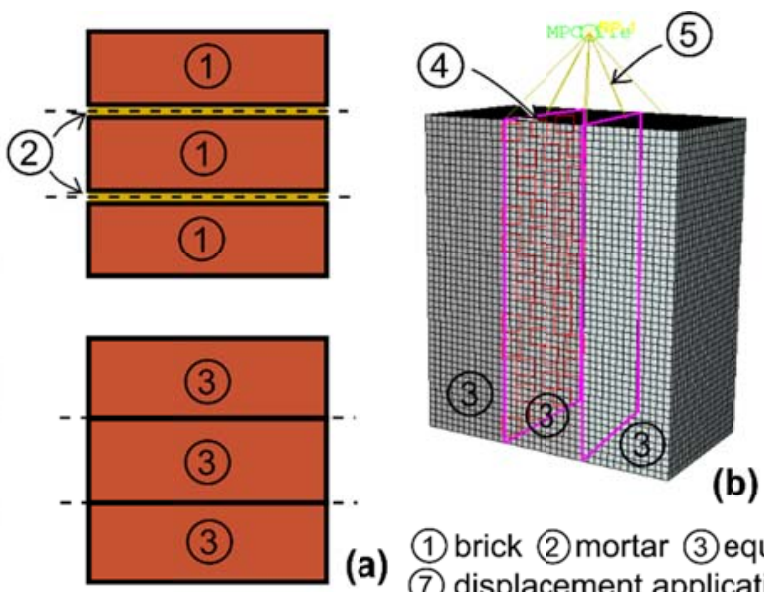

(b)

(8) (9)
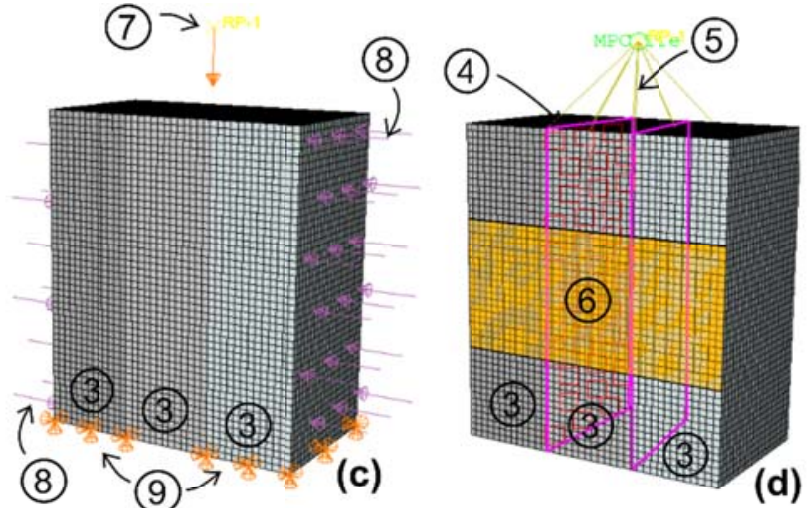

(1) brick (2)mortar (3) equivalent brick (4) interface (5)multi-point tie (6) membrane (7) displacement application point (8) precompression stress (9) boundary conditions
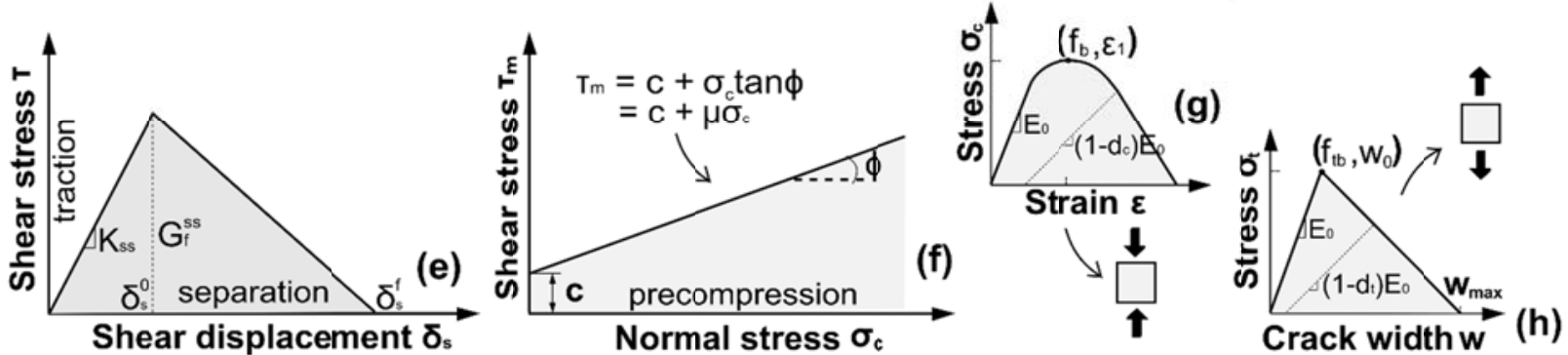

Figure 9 Modelling procedures: a) simplified micro-modelling (block based) approach, b) triplet model with brick-to-brick interface highlighted, c) triplet model with loads and boundary conditions, d) strengthened triplet with horizontal FRP strips,

e) cohesive behaviour, f) Mohr-Coulomb criterion, $g$ ) compressive modelling of bricks, h) tension modelling of bricks.
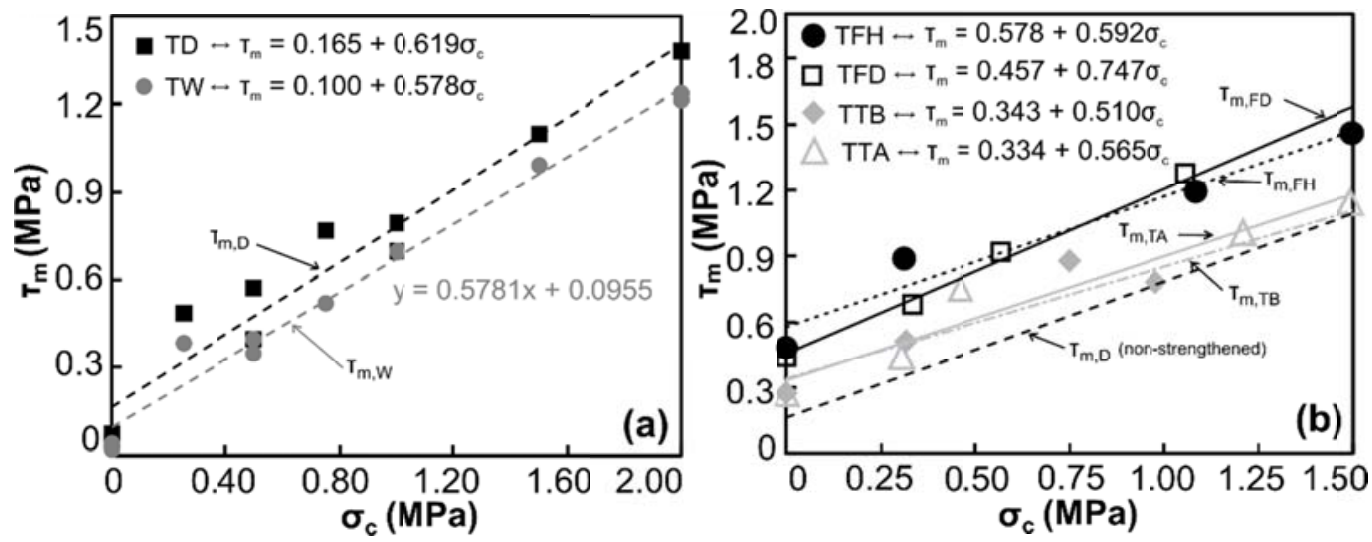

Figure 10 Relationship between shear strength and pre-compression level $\left.\left(\tau_{m}-\sigma_{c}\right): a\right)$ non-strengthened triplets, b) strengthened triplets 

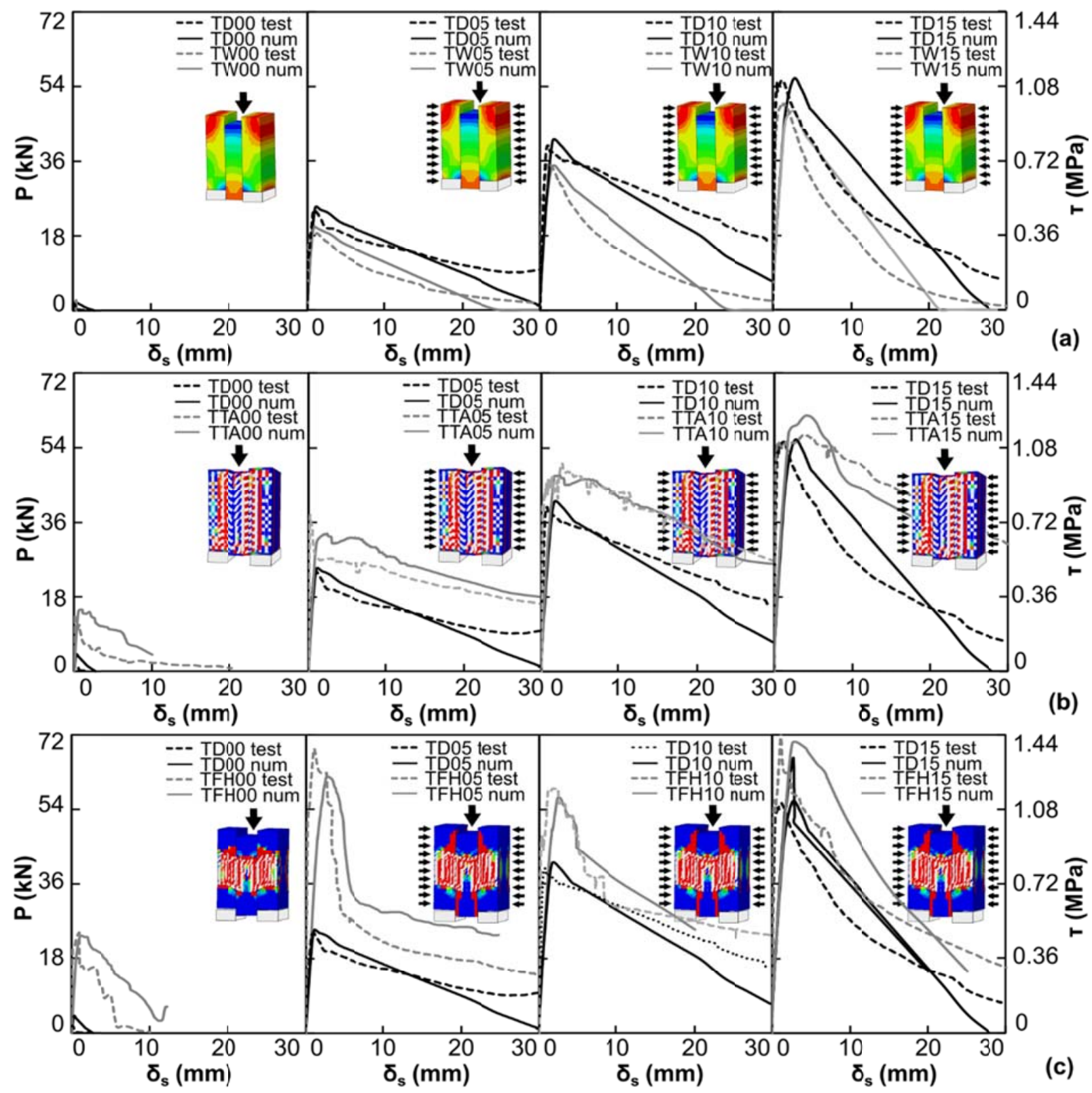

Figure 11 Comparative assessment between numerical results of TD models and a) TW models, b) TTA models, c) TFH models. 


\section{Tables}

Table 1a Results from non-strengthened triplet shear tests

\begin{tabular}{|c|c|c|c|c|c|}
\hline Specimen $->$ & \multicolumn{2}{|c|}{ TD } & \multicolumn{2}{c|}{$\mathrm{TW}$} & \\
\hline$\sigma_{\mathrm{c}}(\mathrm{MPa})$ & $\tau_{\mathrm{m}, \mathrm{D}}(\mathrm{MPa})$ & $\mathrm{CoV}(-)$ & $\tau_{\mathrm{m}, \mathrm{W}}(\mathrm{MPa})$ & $\mathrm{CoV}(-)$ & $\tau_{\mathrm{m}, \mathrm{W}} / \tau_{\mathrm{m}, \mathrm{D}}(-$ \\
\hline & 0.06 & 0.35 & 0.03 & 0.47 & 0.50 \\
\hline 0.00 & 0.49 & - & 0.38 & - & 0.78 \\
\hline 0.25 & 0.48 & 0.25 & 0.37 & 0.10 & 0.77 \\
\hline 0.50 & 0.77 & - & 0.52 & - & 0.68 \\
\hline 0.75 & 0.75 & 0.08 & 0.70 & 0.01 & 0.93 \\
\hline 1.00 & 1.10 & - & 0.99 & - & 0.90 \\
\hline 1.50 & 1.38 & 0.00 & 1.23 & 0.02 & 0.89 \\
\hline 2.00 & 1.57 & 0.06 & 1.33 & 0.03 & 0.85 \\
\hline
\end{tabular}

Notes: (i) $\tau_{m, D}$ and $\tau_{m, W}$ represent average values of shear strength; (ii) one sample was tested for $\sigma c=0.25,0.75,1.50 \mathrm{MPa}$ and a minimum of two samples were tested for $\sigma c=0,0.50,1.00,2.00$ and 2.50 MPa.

Table $1 \mathrm{~b}$ Results from strengthened triplet shear tests

\begin{tabular}{|c|c|c|c|c|c|c|c|c|}
\hline $\begin{array}{c}\text { Specimen } \\
->\end{array}$ & \multicolumn{2}{|c|}{ TFH } & \multicolumn{2}{c|}{ TFD } & \multicolumn{2}{c|}{ TTA } & \multicolumn{2}{c|}{ TTB } \\
\hline$\sigma_{\mathrm{c}}(\mathrm{MPa})$ & $\begin{array}{c}\tau_{\mathrm{m}, \mathrm{FH}} \\
(\mathrm{MPa})\end{array}$ & $\begin{array}{c}\tau_{\mathrm{m}, \mathrm{FH}} / \\
\tau_{\mathrm{m}, \mathrm{D}} \\
(-)\end{array}$ & $\begin{array}{c}\tau_{\mathrm{m}, \mathrm{FD}} \\
(\mathrm{MPa})\end{array}$ & $\begin{array}{c}\tau_{\mathrm{m}, \mathrm{FD}} / \\
\tau_{\mathrm{m}, \mathrm{D}} \\
(-)\end{array}$ & $\begin{array}{c}\tau_{\mathrm{m}, \mathrm{TA}} \\
(\mathrm{MPa})\end{array}$ & $\begin{array}{c}\tau_{\mathrm{m}, \mathrm{TA}} / \\
\tau_{\mathrm{m}, \mathrm{D}} \\
(-)\end{array}$ & $\begin{array}{c}\tau_{\mathrm{m}, \mathrm{TB}} \\
(\mathrm{MPa})\end{array}$ & $\begin{array}{c}\tau_{\mathrm{m}, \mathrm{TB}} / \\
\tau_{\mathrm{m}, \mathrm{D}} \\
(-)\end{array}$ \\
\hline 0.00 & 0.48 & 8.00 & 0.44 & 7.33 & 0.28 & 4.67 & 0.34 & 5.67 \\
\hline 0.25 & 0.57 & 1.16 & 0.64 & 1.31 & 0.42 & 0.86 & 0.47 & 0.96 \\
\hline 0.50 & 1.37 & 2.85 & 0.89 & 1.85 & 0.56 & 1.17 & 0.6 & 1.25 \\
\hline 1.00 & 1.19 & 1.55 & 1.11 & 1.44 & 0.84 & 1.09 & 0.85 & 1.10 \\
\hline 1.50 & 1.45 & 1.32 & 1.55 & 1.41 & 1.12 & 1.02 & 1.11 & 1.01 \\
\hline
\end{tabular}

Notes: $\tau_{m, F H,} \tau_{m, F D,} \tau_{m, T A}$ and $\tau_{m, T B}$ are obtained from a single specimen.

Table 2 Properties of dry materials

\begin{tabular}{|c|c|c|c|c|}
\hline $\begin{array}{c}\mathrm{E}_{\mathrm{m}} \\
(\mathrm{MPa})\end{array}$ & $\begin{array}{c}\mathrm{f}_{\mathrm{m}} \\
(\mathrm{MPa})\end{array}$ & $\begin{array}{c}\mathrm{G}_{\mathrm{m}} \\
(\mathrm{MPa})\end{array}$ & $\begin{array}{c}\mathrm{f}_{\mathrm{tm}} \\
(\mathrm{MPa})\end{array}$ & $\begin{array}{c}\mathrm{h}_{\mathrm{m}} \\
(\mathrm{mm})\end{array}$ \\
\hline 282.00 & 1.28 & 117.50 & 0.28 & 14.4 \\
\hline $\begin{array}{c}\mathrm{E}_{\mathrm{b}} \\
(\mathrm{MPa})\end{array}$ & $\begin{array}{c}\mathrm{f}_{\mathrm{b}} \\
(\mathrm{MPa})\end{array}$ & $\begin{array}{c}\mathrm{G}_{\mathrm{b}} \\
(\mathrm{MPa})\end{array}$ & $\begin{array}{c}\mathrm{f}_{\mathrm{tb}} \\
(\mathrm{MPa})\end{array}$ & $\begin{array}{c}\mathrm{h}_{\mathrm{b}} \\
(\mathrm{mm})\end{array}$ \\
\hline 620.00 & 5.39 & 258.33 & 0.92 & 66 \\
\hline
\end{tabular}

Table 3 Shear fracture energy values

\begin{tabular}{|c|c|c|c|c|c|c|}
\hline Specimen -> & TD & TW & TFH & TFD & TTA & TTB \\
\hline$\sigma_{\mathrm{c}}(\mathrm{MPa})$ & $\begin{array}{c}\mathrm{G}_{\mathrm{fs}, \mathrm{D}} \\
(\mathrm{N} / \mathrm{mm})\end{array}$ & $\begin{array}{c}\mathrm{G}_{\mathrm{fs}, \mathrm{W}} \\
(\mathrm{N} / \mathrm{mm})\end{array}$ & $\begin{array}{c}\mathrm{G}_{\mathrm{fs}, \mathrm{FH}} \\
(\mathrm{N} / \mathrm{mm})\end{array}$ & $\begin{array}{c}\mathrm{G}_{\mathrm{fs}, \mathrm{FD}} \\
(\mathrm{N} / \mathrm{mm})\end{array}$ & $\begin{array}{c}\mathrm{G}_{\mathrm{fs}, \mathrm{TA}} \\
(\mathrm{N} / \mathrm{mm})\end{array}$ & $\begin{array}{c}\mathrm{G}_{\mathrm{fs}, \mathrm{TB}} \\
(\mathrm{N} / \mathrm{mm})\end{array}$ \\
\hline 0 & 0.01 & 0.01 & 2.48 & 1.36 & 1.32 & 0.81 \\
\hline 0.5 & 7.48 & 4.61 & 16.14 & 11.40 & 13.51 & 17.18 \\
\hline 1 & 14.41 & 8.12 & 19.94 & 21.27 & 22.58 & 15.89 \\
\hline 1.5 & 14.94 & 10.29 & 21.64 & 24.15 & 27.11 & 24.66 \\
\hline 2 & 17.45 & 10.86 & - & - & - & - \\
\hline
\end{tabular}

